\title{
Los orígenes del neoestructuralismo latinoamericano
}

Carlos Mallorquín Suzarte

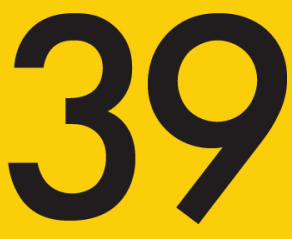

MAYO/ JUNIO

2017

estudios regionales en
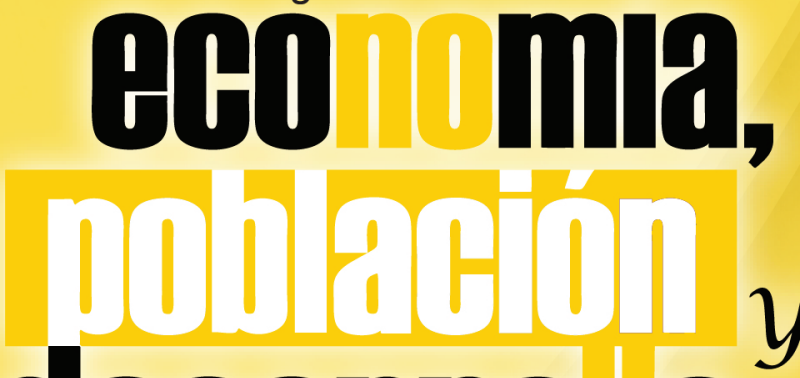

desarpo o

cuadernos de trabajo de la UACJ 


\title{
Los orígenes del neoestructuralismo latinoamericano
}

\author{
Carlos Mallorquín Suzarte
}

UNIVERSIDAD AUTÓNOMA DE CIUDAD JUÁREZ 


\title{
UNIVERSIDAD AUTÓNOMA DE CIUDAD JUÁREZ \\ Instituto de Ciencias Sociales y Administración
}

\author{
Cuerpo Académico de Estudios Regionales en \\ Economía, Población y Desarrollo
}

Lic. Ricardo Duarte Jáquez

Rector

M.C. David Ramírez Perea

Secretario General

Mtro. Juan Ignacio Camargo Nassar

Director del Instituto de Ciencias

Sociales y Administración

Mtro. Ramón Chavira Chavira

Director General de Difusión

Cultura y Divulgación Científica

Dr. Luis Enrique Gutiérrez Casas

Coordinador General de

Investigación y Posgrado

\section{Dr. Jaime Alberto Arellano Quiroga \\ Coordinador del Cuerpo Académico de \\ Estudios Regionales en Economía, Población y Desarrollo}

Director y editor

Dr. Luis Enrique Gutiérrez Casas

Comité editorial

Sección internacional

Dra. Sofía Boza Martínez (Universidad de Chile, Chile)

Dra. Olga Biosca Artiñano (Glasgow Caledonian

University, Reino Unido)

Dra. Ángeles Sánchez Díez (Universidad Autónoma de

Madrid, España)

Dr. Thomas Fullerton Mankin (University of Texas at

E1 Paso, Estados Unidos)

Dr. Adrián Rodríguez Miranda (Universidad de la

República, Uruguay)

Sección local

(Universidad Autónoma de Ciudad Juárez)

Dra. Myrna Limas Hernández

Dra. Ikuho Kochi

Dr. Raúl Alberto Ponce Rodríguez

Dr. Isaac Leobardo Sánchez Juárez

Dr. Héctor Alonso Barajas Bustillos

Diseño de cubierta Abigail Bautista
Estudios Regionales en Economía, Población

y Desarrollo. Cuadernos de Trabajo de la UACJ

ISSN 2007-3739

Número 39. Mayo/ Junio 2017

Los orígenes del neoestructuralismo latinoamericano

Carlos Mallorquín Suzarte

Universidad Autónoma de Ciudad Juárez

Estudios Regionales en Economía, Población y Desarrollo. Cuadernos de Trabajo de la UACJ

Año 7, No. 39 mayo - junio 2017, es una publicación bimestral editada por la Universidad Autónoma de Ciudad Juárez a través del Cuerpo Académico de Estudios Regionales en Economía, Población y Desarrollo del Instituto de Ciencias Sociales y Administración. Redacción: Avenida Universidad y H. Colegio Militar, Zona Chamizal s/n., C.P. 32300, Ciudad Juárez, Chihuahua, México. Teléfonos: (656) 688-38-00, ext. 3792. Correo electrónico: lgtz@uacj.mx.

Editor responsable: Luis Enrique Gutiérrez Casas. Reserva de derechos al uso exclusivo No. 04-2011-021713353900-102. ISSN 2007-3739, Impresa por Studio Los Dorados, calle Del Campanario, número 820-2, Santa Cecilia, C.P. 32350, Cd. Juárez, Chihuahua. Distribuidor: Subdirección de Gestión de Proyecto y Marketing Editorial. Ave. Plutarco Elías Calles 1210, Foviste Chamizal, C.P. 32310, Ciudad Juárez, Chihuahua. Este número se terminó de imprimir el 15 de marzo 2017 con un tiraje de 120 ejemplares.

Los ensayos publicados son responsabilidad exclusiva de sus autores. Se autoriza la reproducción total o parcial bajo condición de citar la fuente.

\section{Registrada en:}

Publicación afiliada a la Red Iberoamericana de Estudios del Desarrollo

Universidad Autónoma de Ciudad Juárez

Ave Plutarco Elías Calles 1210

Foviste Chamizal, C.P. 32310

Ciudad Juárez, Chihuahua, México

www.uacj.mx

(C) Universidad Autónoma de Ciudad Juárez 
Estudios Regionales en Economía, Población y Desarrollo. Cuadernos de Trabajo de la UACJ, Universidad

Autónoma de Ciudad Juárez , número 39, mayo-junio de 2017, ISSN 2007-3739, pp. 3-30, México.

\title{
Los orígenes del neoestructuralismo latinoamericano
}

\author{
Carlos Mallorquín Suzarte*
}

\begin{abstract}
Resumen
Este ensayo propone dar cuenta de la ambigüedad del concepto 'neostructuralismo' cuando se le analiza a partir de la óptica de la obra de Osvaldo Sunkel; no obstante, ello no excluye una posible reconstrucción del término a partir de una reflexión en torno a sus autores "primigenios" y los respectivos vocabularios sobre el 'estructuralismo'. Sin embargo, el concepto 'neostructuralismo' no armoniza necesariamente con la obra de Sunkel y, paradójicamente, tampoco con la obra de Raúl Prebisch antes del primer lustro de la década de 1970, sino hasta la publicación de la obra "Capitalismo periférico, crisis y transformación". Por lo tanto, la excursión conceptual que hacemos sobre el 'estructuralismo' y el 'neostructuralismo' da a entender que este último es fruto del progreso teórico dentro del pensamiento latinoamericano, bajo la singularidad con que Sunkel se integró al mismo.
\end{abstract}

Palabras clave: Estructuralismo, neoestructuralismo, Latinoamérica.

\begin{abstract}
This essay aims to analyse the origin of 'latinoamerican neostructuralism' and highlight its ambiguity based in the intellectual work of Osvaldo Sunkel. This does not exclude a possible reconstruction of the concept starting from the standpoint of the first authors that developed the 'estructuralist' theory. However, the term 'neoestructuralism' does not necessarily harmonizes with the Sunkel approach and, paradoxically, not even with Raúl Prebisch's perspective before the first half of the 1970s, until the publication of the book "Peripheral capitalism, crisis and transformation". Therefore, the conceptual journey we make between 'estructuralism' and 'neostructuralism' help us to understand that the latter is the result of the theoretical progress in Latin American thinking, under the uniqueness of Sunkel thought.
\end{abstract}

Key words: Estructuralism, neoestructuralism, Latinoamerican thought.

JEL Classification: B20, B31.

- Recibido en: Febrero de 2017

- Aprobado en: Abril de 2017

* Profesor del Centro de Estudios para el Desarrollo de la Universidad Autónoma de Zacatecas, México. Correo electrónico: carlosmallorquin1@gmail.com. 


\section{$\ni$ 1. Introducción.}

Debemos examinar y discutir la conveniencia y limitaciones de la denominación neoestructuralismo latinoamericano. La reciente aparición del concepto en el libro: "Neoestructuralismo y corrientes heterodoxas en América Latina y el Caribe a inicios del siglo XXI" (Barcena, Prado, 2015), haciendo referencia al pensamiento de Raúl Prebisch, abre un amplio campo para su discusión (Mallorquin, 2017a).

Procederemos problematizando la construcción que dicho libro hace de la fisonomía del neoestructuralismo y de la contribución de Osvaldo Sunkel a la misma, que culmina aparentemente en 1991 con la publicación del libro coordinado por Sunkel (1991): "El desarrollo desde dentro; un enfoque neoestructuralista para América Latina". Estrictamente hablando, su intervención en dicho libro consta del primer capítulo: "Del desarrollo hacia adentro al desarrollo desde dentro" (Sunkel, 1991a), es coautor, con Joseph Ramos, de la introducción (Ramos, Sunkel, 1991) y del prólogo (Sunkel, 1991b). Sin duda Sunkel colonizó el liderazgo intelectual de la época; no obstante, si examinamos el período 1987-1991, ${ }^{1}$ tomando como referencia el ángulo de la intervención de Sunkel, la reciente interpretación sobre su asociación al neoestructuralismo desconoce la singularidad teórica de sus ideas sobre el desarrollo por ese entonces.

No se trata de subrayar el hecho de que el propio Raúl Prebisch negó la pertinencia del vocablo para referirse a sus ideas, porque la designación conceptual puede ser un mecanismo de utilidad pragmática para intentar explicar ciertas concepciones. El objetivo aquí es remarcar que el período explorado de la obra de Sunkel en torno al desarrollo no presenta similitudes al estructuralismo o neoestructuralismo -que entonces se empieza a discutir- y su perspectiva en la región, aunque indudablemente representa un fruto del progreso teórico regional generado originalmente al amparo de la "extraordinaria contribución” de Prebisch (Sunkel, 1987: 296).

Si partimos desde la óptica teórica de Sunkel, quien en 1987 ya señalaba su discrepancia respecto a la perspectiva centro-periferia, haciendo perentoria la necesidad de "reconstruir la teoría del desarrollo" (Sunkel, 1987: 350), ${ }^{2}$ la búsqueda en alguna época y los discursos correspondientes para sistematizar el uso del neoestructuralismo se hace casi imposible.

En el libro reciente, Pérez Caldentey sintetiza la aparición del neostructuralismo:

El neoestructuralismo se desarrolló a partir del documento Transformación productiva con equidad (CEPAL, 1990) y del libro compilado por Osvaldo Sunkel, El desarrollo desde dentro: un enfoque neoestructuralista para América Latina (1991). La elaboración de esta teoría constituye un esfuerzo para integrar al pensamiento estructuralista los cambios

1 Curiosamente, se agradece el aporte de G. Zuleta para la elaboración de la "Introducción”, (Ramos, Sunkel, 1991) pero las páginas 17 a 30, aparecen, también en el texto (Sunkel y Zuleta, 1990).

2 En Mallorquin 2017, hago un recuento de su visión de “juventud”, resaltando igualmente su posicionamiento muy singular respecto la perspectiva centro-periferia e ideas de Prebisch.

- Economía, Población y Desarrollo. Cuadernos de Trabajo de la UACJ, núm. 39, may-jun 2017 
que ocurrieron en la región y a nivel internacional desde fines de los años ochenta, que incluyen la apertura comercial, la movilidad internacional de capitales, la privatización y la desregulación en un contexto de relaciones más estrechas con el resto del mundo y de mayor integración regional (Bielschowsky, 2009; Sunkel y Zuleta, 1990). (Perez Caldentey, en Barcena, Prado, 2015: 51) ${ }^{3}$.

Bielschowsky ha especificado la inexorable evolución entre un evento discursivo fundacional estructuralista y la reconfiguración que le sigue:

“... pese a los importantes cambios introducidos a partir de 1990 para adecuarse a las nuevas condiciones históricas, el pensamiento neoestructuralista es muy similar al estructuralista. El prefijo neo viene al caso para indicar la adaptación a los tiempos de apertura y desregulación, pero la base analítica de la nueva etapa sigue siendo estructuralista" (Bielschowsky, 2009: 184).

Existe consenso que el movimiento de superación y transformación teórica del estructuralismo latinoamericano en neoestructuralismo se dice heredero de la obra de Raúl Prebisch. El libro de reciente data (Barcena, Prado, 2015), tiene como uno de sus objetivos en parte rehabilitar a Prebisch, y al neoestructuralismo latinoamericano para lograr un "diálogo" con el pensamiento "heterodoxo". Mi apreciación (Mallorquin, 2017a), es que dicha discusión tiende a "domesticar" lo aspectos teóricos más fructíferos que ofrece Prebisch y el estructuralismo latinoamericano para pensar la problemática de la justicia y la transformación social. Parafraseando a Ocampo, Hernández ha dicho (a nota de pie de página): "La CEPAL sustentó la defensa de la industrialización a partir de una teoría de la acumulación del capital, más que de una teoría de la eficiencia económica" (Hernández en Barcena, Prado, 2015: 347); habría que ir más lejos: la industrialización como uno de los medios, entre otros, para alcanzar una mayor justicia distributiva; no se trataba de negarles o arrancarles, a los centros - como decía Prebisch-, los frutos del progreso técnico logrados por sus esfuerzos, pero sí de que se "permita" a la periferia esa opción a través de sus propios empeños. En otras palabras, el núcleo del estructuralismo surgió para pensar, superar, las asimetrías de poder entre centro y periferia: la heterogeneidad generada por dichas asimetrías, relaciones que se presentan a lo largo del ámbito social, "dentro" y "fuera" de un mismo "país"4.

3 Pérez Caldentey, Hernández, Ocampo, testimonian la importancia de la figura de Sunkel en el reciente libro (Barcena, Prado: 2015), y por su parte Guillen, 2007, Leiva, 2008, Meireles, 2016.

4 "Consideraremos -dice Prebisch-que la etapa de producción primaria se realiza en la periferia y que las otras etapas de elaboración y expendio en el centro cíclico. No es ésta la única característica de los centros cíclicos, hay otros (...) Quiero decir que un centro cíclico y una periferia pueden estar contenidas en un mismo país, como en los Estados Unidos que tienen un gran periferia, contrariamente a lo que ocurría en el centro cíclico británico que tenía como periferia la economía mundial."(1949a: 34-35, subrayados míos). Muchos años después, el 13 de junio de 1971, en la "tercera clase" en Santiago de Chile, Prebisch reitera lo mismo: "pues bien, entremos, ahora en este tema tan debatido, que tiene que explicar a la vez el deterioro interno y el deterioro externo. Es decir, no sólo el deterioro entre centro y periferia, sino también el deterioro entre el centro en la periferia y la periferia, y entre la periferia y [su C.M.] periferia. No se trata de un juego de palabras. Existe también un tipo de relaciones centro y periferia dentro de la periferia"(1971: p.3-4). 


\section{$\rightarrow$ 2. La búsqueda del desarrollo perdido.}

La perspectiva centro-periferia o estructuralismo latinoamericano, empieza a ser el centro de atención en varias reflexiones en el año de 1988-89. En parte, ello obedece a la discusión generada por el artículo de Sunkel en 1987: "Las relaciones Centro-Periferia y la transnacionalizacion" (1987). Más allá de un debate académico, se trataba de ofrecer ideas para cambiar el rumbo económico que presentaba la región. También es secuela de una tasa de crecimiento cero en la región latinoamericana durante la "década perdida" (1980), obligaba a dar una respuesta y explicación que provoque una alternativa en materia de política económica y por el otro, intentar contrarrestar teóricamente el historial negro fomentado por el neoliberalismo sobre el desarrollo y crecimiento regional de las décadas previas.

Dicha disposición por parte del discurso "estructuralista" refleja la hegemonía abrumadora del "neoliberalismo", a nivel de las instituciones internacionales (Banco Mundial, FMI), ante la negativa internacional de otorgar préstamos para apoyar nuevos proyectos de inversión y reestructuración de las respectivas deudas si no se realizaban las "reformas estructurales", cuyas características principales culminaron en aquello que se llegó a denominar en la década de 1990 como el “Consenso de Washington".

El vocabulario neoliberal o neoclásico que vino a dominar el horizonte de las discusiones en materia de "desarrollo" o "crecimiento" ofrece nada menos que la sensación de un déjà-vú: un retorno a planteamientos que se habían superado en la década de 1950, pero esta vez bajo la Manu Militari. No obstante, el neoliberalismo (Connell, 2014) "realmente existente", así como las políticas de "estabilización", son elaboraciones que surgieron en la región latinoamericana o en el Sur; sus "reglas" e implementación fueron muy diferentes a las que se intentaron difundir en el Norte a partir de los años del reino de Thatcher, lo cual demuestra, una vez más, que en los "centros", las asimetrías de poder y sus condiciones de existencia, difieren de las que existen en la periferia, posibilitando la defensa de sus ingresos respectivos.

Casi a fines de la década 1980, la impugnación -por parte de algunos adeptos o conocedores del pensamiento latinoamericano-, a las interpretaciones neoliberales del estructuralismo

5 Ffrench-Davis, R. (1991).

6 Para cualquier acercamiento estadístico, sectorial y macroeconómico sobre la región actual véase (Barcena, Prado, 2015), por su parte el libro compilado por Sunkel (Sunkel, 1991), ofrece las de la época que fundamentan muchas de las hipótesis.

7 Cfr., (Bitar, 1988); (Griffith-Jones, S., Sunkel, O., 1986), (Sunkel, 1984), (Ugarteche, 2014), Bulmer - Thomas (2011), entre otros.

8 Cfr., (Hernández, en Bárcena, Prado, 2015: 349-350). Hernández dice que en "los países siguieron diferentes trayectorias y se acogieron al Consenso de Washington con diferentes grados de sumisión y, sobre todo, de agresividad o cautela en la implementación de las reformas (Hernández, en Bárcena, Prado, 2015: 341), también: (Cypher, 1988); (Kregel, 2008).

9 Recientemente, Grecia -la “periferia” de Europa”, sufre las mismas condicionalidades del FMI y BM. 
latinoamericano, así como las políticas económicas fomentadas por parte de los gobiernos locales de la región, asume la forma, por un lado, de señalar una inadecuada comprensión de sus fundamentos doctrinarios originales, y por otro, intentar distanciarlos de las políticas gubernamentales del pasado. Todo lo cual sólo lograba certificar el triunfo de la ficción neoliberal sobre la evolución, condiciones e impotencia de las economías de la periferia. Hoy incomoda, por no usar otro término, que entre las primeras exposiciones en torno a las ideas de Prebisch y del estructuralismo latinoamericano, el intento por neutralizar y aclarar los equívocos del neoliberalismo, se inicia casi pidiendo permiso. Apoyándose en Prebisch, Rosales dice:

A riesgo de ser reiterativo, en aras de la objetividad en el debate es necesario insistir en que esta preocupación estuvo siempre presente en los escritos que dieron origen al estructuralismo latinoamericano. 'Es necesario definir con precisión el objeto que se persigue mediante la industrialización. Si se aspira a la autarquía, entonces las consideraciones económicas pasan a segundo plano y sería admisible cualquier industria que sustituya importaciones. Pero si el objetivo es elevar el nivel de vida de las masas, hay que tener presentes los límites más allá de los cuales una mayor industrialización podría significar una merma de productividad' (Prebisch, 1950), (Rosales, 1988b: 31, subrayados míos).

No obstante, la recuperación del vocabulario "estructuralista" para hacer frente a dicho espectro teórico no elude mencionar simultáneamente y de manera crítica, las consecuencias negativas de ciertas estrategias de desarrollo regionales. Al respecto, Rosales dice:

i) un patrón de inserción comercial que conduce a una especialización empobrecedora; ii) un patrón productivo desarticulado y vulnerable, altamente heterogéneo, que concentra el progreso técnico, incapaz de absorber productivamente el incremento de la fuerza de trabajo y volcado a atender las demandas de una minoría de la población; iii) una distribución del ingreso altamente concentrada y excluyente, reflejando la coexistencia de elevados niveles de crecimiento (precrisis de la deuda) con la incapacidad de reducir significativamente la evolución de la pobreza extrema (Rosales 1988a: 406).

10 “Aun así, esta relativa aproximación a nivel de las propuestas (derivada tal vez de experiencias frustrantes de uno y otro signo, de las propias condiciones de crisis que se prolongan dolorosa e interminablemente, y de la mayor desideologización y mayor pragmatismo que comienzan a imperar en estos primeros años de posguerra fría) no modifica la diferencia fundamental en lo que se refiere a premisas axiomáticas y filosóficas que subyacen a ambas propuestas. No es del caso ahondar sobre esta cuestión en esta oportunidad, pues ello pertenece a otro nivel de abstracción. Sin embargo, es conveniente recordar, aunque sea muy esquemáticamente, que el liberalismo y el estructuralismo, y sus correspondientes versiones neos conciben y explican de modo muy diferente el comportamiento del individuo en sociedad" (Sunkel y Zuleta, 1990: 48-49, subrayados míos).

11 Otra cita de Prebisch que subraya Rosales por la época: "se desenvuelve en compartimentos estancos y altamente protegidos por una barrera de elevados aranceles, por restricciones y prohibiciones que eliminan la competencia exterior y dificultan la penetración del progreso técnico, así como el buen aprovechamiento de los factores productivos... Industrialización ineficiente y costosa por la consabida estrechez de los mercados y el débil acicate de la competencia. Lleva dentro de sí misma el germen de su propio debilitamiento dinámico, pues se desenvuelve en un régimen autónomo de costos y precios que - al no tener contacto con el mercado internacional—, desalienta las exportaciones de productos industriales, que son verdaderamente indispensables, como que la industria necesita salir hacia fuera para desenvolverse hacia adentro en profundidad" (Prebisch, 1970, pp. 205-206). (Rosales, 1988b: 26). 
No obstante, tanto la distinción entre el estructuralismo, y el "propiamente latinoamericano", realizada por Sunkel y que da forma a los diagnósticos y explicaciones sobre la región latinoamericana, pueden convertirse, a su vez, en fuente de debates interpretativos dadas las respectivas exégesis de Prebisch o del pensamiento de la CEPAL.

La diferenciación que plasmó el propio Sunkel, subrayando divergencias palpables entre ellas, es un aspecto teórico sobre el cual insistió:

el estructuralismo - al menos en su versión latinoamericana- (Sunkel y Zuleta, 1990:49) (...); [o] la perspectiva propiamente latinoamericana, [de] la actual corriente de pensamiento denominada neoestructuralismo afirma, en lo fundamental, que los problemas económicos principales y la condición de subdesarrollo que aún prevalecen en los países latinoamericanos no se deben tanto a distorsiones inducidas por la política sino que más bien son de origen histórico y de índole endógena y estructural. (Sunkel y Zuleta, 1990:42, subrayados míos) (...) Tales propuestas se inspiran en especial, pero no en forma exclusiva ni excluyente, en la vertiente de pensamiento estructuralista latinoamericano, renovada y reformulada con la contribución neoestructuralista que ha surgido en la última década. (Ramos, Sunkel; 1991:17 subrayados míos). ${ }^{12}$

Aunque aquí nos hemos anticipado a la culminación de las conclusiones a las que llegó Sunkel; vale la pena no obstante examinar la evolución de la mutación teórica que generó las secuelas teóricas que nos siguen hasta el día de hoy.

Asumió el liderazgo teórico del discurso sobre el neoestructuralismo cuya propagación transmitió una perspectiva muy singular en la época: la estrategia y construcción inicia a partir de una lectura e interpretación de ciertos textos clásicos de Prebisch, que a su vez la acopla a su propia evolución teórica.

La interpretación en "Las relaciones Centro-Periferia y la transnacionalización" (Sunkel, 1987), procede a partir del rescate de un giro lingüístico conceptual en Prebisch; una diferencia específica, aparentemente inadvertida, en torno a la fuente del impulso que generó el crecimiento de la región en distintos períodos. Es de esta manera que restaura a Prebisch o al estructuralismo latinoamericano como sustento del neoestructuralismo. Retrospectivamente sabemos que los esfuerzos

12 La cita de Sunkel y Zuleta se encuentra en (Sunkel, Zuleta, 1990: 36). En el Prólogo (Sunkel, 1991b) a Sunkel (1991), se subrayaba que el libro presentaba "características novedosas" en relación a la visión neoclásica y el "propio neoestructuralismo" intentando articular: "contribuciones del estructuralismo de los años sesenta, y del neoestructuralismo, en un intento por contribuir a la recuperación y puesta al día del pensamiento económico latinoamericano (...) Desde luego, se caracteriza por un enfoque histórico-estructural de mediano y largo plazo, procurando (...) establecer sistemáticamente la indispensable relación entre dicha perspectiva y la coyuntura a corto plazo. Esto contrasta con los postulados neoclásicos y los enfoques neoestructuralistas iniciales que privilegian casi exclusivamente los equilibrios en los flujos económicos de corto plazo, los mercados y los precios. Igualmente se diferencia de la escuela estructuralista que tendía a soslayar estos aspectos" (...) da[ndo] especial importancia a los recursos productivos -capital, trabajo, recursos naturales y tecnología- (...) una base esencialmente ampliada y enriquecida para el relanzamiento del crecimiento y el desarrollo. (...) este hincapié en el potencial productivo propio difiere del neoliberalismo y del neoestructuralismo por razones señaladas previamente, pero también se diferencia del estructuralismo. (1991b: 10), (...) El pensamiento económico en materia de desarrollo fue vigoroso y creativo en los años cincuenta, particularmente en la región. Aquí se generaron las concepciones Centro-Periferia y de la heterogeneidad estructural, y los enfoques estructuralista y de dependencia. Pero desde comienzos de los setenta esta escuela de pensamiento perdió vitalidad y vigencia“ (1991b: 11-12). 
de las exposiciones ofrecidas sobre el estructuralismo por parte de Rosales (1988a, 1988b); Bitar (1988); Lustig (1988); French-Davis (1988), Pinto (1989), son de "otra naturaleza", y fueron en vano, para entonces, el neoestructuralismo ya ocupaba, institucionalmente un lugar de predominio en la CEPAL. La literatura señalada, que antecede a dicho momento, pareciera ofrecer un vocabulario con mayor apego a Prebisch, o hasta entonces "ortodoxia" CEPALina. Pero nuevamente nos estamos adelantando.

En "Las relaciones Centro-Periferia y la transnacionalizacion" (Sunkel, 1987), la interpretación de Prebisch y "aproximación” al estructuralismo es definitiva: de hecho, cuestiona cierta interpretación de Prebisch por toda la "tradición” "estructuralista”, en la cual él se incluye a sí mismo 15 años después. Destaco éste dato, porque si nuestra lectura de Sunkel es correcta, su vocabulario sui generis ya lo ubicaba al borde del perímetro del discurso en cuestión.

Antes de describir esta transformación teórica, vale la pena indagar el punto de partida desde el cual realizará el salto teórico, y el sustento conceptual correspondiente. Comprender la transición y culminación teórica-política entre 1987 y 1990, implica recordar la valentía de la misma: deja atrás todo una perspectiva y escritos "dependentistas" y simultáneamente lleva a cuestas una "relectura" y/o "ruptura" respecto el vocabulario "prebischiano", convirtiéndose en el héroe intelectual del neoestructuralismo.

\section{$\rightarrow$ 3. Causalidad y determinación: "desde afuera" y "hacia adentro".}

Previamente, sus escritos habían culminado en un grado extremo de decepción y pesimismo sobre las posibilidades de un "desarrollo nacional": abundan los diagnósticos sobre la transnacionalización de las economías regionales, la creciente heterogeneidad y polarización económica-social (Sunkel, 1968; 1971; 1977; 1978; 1980), y potencialmente, la "sucursalización" de las economías respecto las empresas transnacionales cuyas sedes se encontraban en el centro, haciéndose cada vez más remota la esperanza de una transformación socialista a corto plazo (Sunkel, 1968). Muchos años habían transcurridos, desde el primer lustro de la década de 1960, cuando la debacle de las "políticas de industrialización vía la sustitución de importaciones" se identificaba como el núcleo teórico y sustento del pensamiento latinoamericano o centro-periferia. Surgió entonces un simple silogismo aparentemente irrefutable, mistificando el vocabulario desarrollista, transformándolo en una especie de "fetichismo de la industrialización" (Lustig, 1988:42). ${ }^{15}$

El examen y análisis del endeudamiento latinoamericano (Sunkel 1984; Griffith -Jones,

13 Sunkel lo reafirma 15 años después: "En la literatura de la CEPAL, en el libro mío con Pedro Paz, en general en artículos de Aníbal Pinto, de Furtado y otros, se habla de la etapa de crecimiento hacia fuera y de la etapa de crecimiento hacia dentro. Bueno, Prebisch no lo escribió así" (Sunkel, 2005: 166). No hay espacio aquí para discutir la lectura de los textos clásicos mencionados por Sunkel (Prebisch, 1949, 1950, 1952), y especialmente al que entonces le decían "la biblia" (Sunkel, 2005:166), lo que aquí está en juego es el uso teórico del mismo y sus consecuencias.

14 Kay, 1989. 
Sunkel, 1986; Bitar, 1988; Bulmer-Tomas, 2011) así como sus propias críticas a las consecuencias de las políticas económicas consumadas en los últimos años, dominaban la narrativa de sus textos en torno al proceso de la "industrialización” y la "desintegración nacional”. Finalmente, los efectos negativos de las lógicas productivas bajo el dominio de las empresas transnacionales, que Sunkel designó como el "conglomerado transnacional" (CONTRA) ${ }^{16}$, reducían el radio de acción de sus efectos e incorporación de la población local debido a su estilo y estrategias de inserción y cálculos en la región: aquí si cabe, literalmente, la acepción anglosajona de goteo (trickle-down).

Mucho del planteamiento puede percibirse en su ensayo de 1987, presentado como "primera aproximación" (1987:31) para explorar algunas "vinculaciones" entre el "pensamiento estructuralista latinoamericano" (1987:31) y la temática de la dependencia:

Queda aquí planteada una fascinante investigación sobre la transición del "desde" al "hacia" en la evolución del pensamiento y la práctica del desarrollo. Nuestra hipótesis preliminar es que los países mayores y que habían logrado un cierto nivel de industrialización en el período precedente iniciaron de hecho su fase de industrialización deliberada con la concepción de una industrialización desde dentro. (..) Se trataba en la mayoría de los casos de producir internamente los insumos importados necesarios para la actividad industrial, de la construcción, minera, agrícola, de transporte. Pero esa orientación matriz, que debería haber avanzado gradualmente a la producción de bienes de capital y la generación de tecnología, se desplazó más bien y crecientemente hacia una industrialización destinada a satisfacer la demanda de bienes de consumo durables de los sectores de los sectores de rentas altas y medias. (Sunkel 1987:43, mis subrayados).

En 1987, la narrativa describe la evolución de un proceso de industrialización latinoamericana y sus efectos, sin mencionar a Fajnzylberg o su vocabulario ("trunca" o "competencia espuria"), cuya inicial lógica de profundización endógena no logró articular plenamente una serie de cadenas y sectores productivos entre sí. El estancamiento del proceso de "industrialización", se explica por el dominio de una lógica productiva centrada en proveer para una demanda de productos de bienes de consumo duraderos para sectores de altos ingresos:

Esta estrategia no está principalmente a la satisfacción de la demanda final de consumo de los ingresos medios y altos (...). Deja abierta las opciones de política para orientar esta industrialización desde dentro hacia los mercados internos y externos (...) El eslabonamiento dinámico no se da principalmente desde la demanda final hacia los insumos y los bienes de capital y la tecnología, sino en buena medida también a la inversa, desde estos

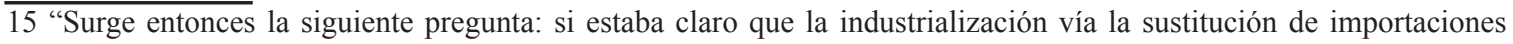
implicaría un deterioro en la balanza comercial durante un período largo (lo cual significa que alguien tenía que estar dispuesto a financiar dicho desequilibrio), ¿cuál era la ventaja de industrializarse por esta vía? Algunos podrían pensar que el pensamiento estructuralista ha sufrido, y sufre, de un fetichismo de la industrialización. En lo que se refiere a las ideas de entonces, que, con ciertas modificaciones, continúan vigentes ahora, se aceptaba la ecuación entre desarrollo e industrialización, porque la experiencia histórica indicaba que la industrialización había sido la forma más eficaz de introducir los cambios tecnológicos y de organización que propiciaron el desarrollo en los países avanzados" (Lustig, 1988: 42). 16 Decía: "la característica sobre saliente del conglomerado transnacional (CONTRA), es la integración de sus actividades, integración que comprende segmentos de las economías de un número considerable de países dentro de los confines de un solo sistema de decisiones" (...) "sistema capitalista internacional contiene un núcleo internacionalizado o transnacionalizado, compuesto por los sectores nacionales integrados y las relaciones entre ellos, y segmentos nacionales excluidos formados por los sectores marginales de cada país y las relaciones entre éstos y los integrados" (Sunkel, 1971:563). 
últimos elementos hacia la satisfacción de las demandas internas y externas consideradas prioritarias en una estrategia de largo plazo. (Sunkel 1987: 42).

El diagnóstico del "nuevo modelo de las relaciones internacionales de posguerra" (Sunkel 1987: 36), exhibe relaciones de dominio y asimetrías de poder aparentemente ineludibles y cabe recordarlo si ponderamos lo que propondrá dos años después:

Las plantas, los laboratorios y los departamentos de diseño y publicidad, así como en las organizaciones de planificación, de toma de decisiones, de personal y de financiamiento que constituyen sus sedes -situadas siempre en un país industrializado- la gran empresa transnacional desarrolla: nuevos productos, nuevas formas de producir esos procesos y los productos intermedios necesarios para su producción, la publicidad necesaria para crear activar sus mercados y las filiales (...) en otros países. En las economías latinoamericanas, por su parte, se van incorporando las diversas etapas de producción de aquellas manufacturas, dando lugar a un proceso de industrialización que avanza en medida importante gracias a la instalación de subsidiarias, la importación de las nuevas maquinarias e insumos y el uso de las marcas, licencias y patentes correspondientes (...) en cierto sentido las estrategias de industrialización basadas en la sustitución de importaciones, así como las posteriores basadas en la promoción de las exportaciones, han sido 'cooptadas' en algún grado como parte de la estrategia de penetración de las empresas trasnacionales en los mercados mundiales y en los propios mercados de sus países de origen. (...) surge una nueva forma de división internacional del trabajo, con su agente correspondiente: el oligopolio manufacturero internacional. Si la interpretación es correcta, se trata de la incorporación a una nueva modalidad del modelo centro-periferia, del cual creíamos que la industrialización por sustitución de importaciones nos estaba liberando (Sunkel 1987: 36).

A dicha descripción de la división internacional del trabajo, y estrategias prácticas de las empresas "oligopólicas" le sigue un bosquejo de las relaciones entre los sectores sociales internos subordinados y los externos dominantes y la progresiva heterogeneidad que presentan las economías. Indica la existencia, de sectores "integrados" a las reglas y rutinas de las economías y empresas transnacionales $^{17}$, tanto económica como culturalmente. Efectivamente, la "creciente brecha" (1987:39) y los indicadores promedios utilizados entre las economías desarrolladas y subdesarrolladas inhiben cualquier alternativa de política económica. Pero Sunkel abandona las clásicas discusiones al respecto: niega la "validez de dichos promedios":

en virtud -dice Sunkel- de la estructura heterogénea de las economías nacionales y de la integración internacional de segmentos de dicha economías, la creciente brecha entre países ricos y pobres sería más bien una especie de ilusión estadística y conceptual, que encubre en la realidad una brecha creciente entre ricos y pobres dentro de los países subdesarrollados, en circunstancias en que el ingreso medio per cápita de los grupos de altos ingresos de estos países se encuentra a niveles absolutos similares y crece con parecida velocidad a la de los grupos medios de los países desarrollados (Sunkel 1987: 39, subrayados míos).

17 Ver la descripción de los gráficos 1 (relaciones de dependencia); 2 (sectores integrados-marginados); 3 (...) núcleo transnacional (Sunkel: 1987: 38-39), y en (Sunkel, 1971). 
Ante dicha polarización socioeconómica (la "transnacionalización”), tanto interna como externa, se reflejan, no obstante, las antiguas relaciones de asimétricas de antaño: "intercambio de productos primarios por manufacturas y relaciones de subordinación internas entre sectores integrados y sectores subordinados y marginados" (Sunkel 1987: 40).

Habiendo descrito el caso del desarrollo de países socialistas y del Japón y países del sudeste asiático, insiste que a pesar del dominio de las relaciones centro-periferia es "posible romper los cercos de la condición periférica e integrarse como socios principales o secundarios, pero activamente participativos y beneficiarios sustanciales del sistema" (Sunkel 1987:44).

En la región latinoamericana el proceso de industrialización, a "partir de la década de 1950" la "expansión acelerada del conglomerado transnacional" (ibid) y una etapa de sustitución de importaciones en la región, "comienza la fase de desnacionalización y sucursalización de algunos sectores de avanzada de la industria latinoamericana" (ibid).

Por otra parte, Sunkel confronta la tesis por excelencia del neoliberalismo: la concepción "autárquica" de las políticas regionales es un mito si se utiliza para explicar las desavenencias del proceso de la industrialización "costosa" y/o "espuria", subrayando que las economías estuvieron controladas en toda su extensión por las poderosas y crecientes vinculaciones con el exterior, particularmente debido a la presencia de las empresas oligopólicas estadounidenses, las cuales durante el proceso de industrialización empeoraron las relaciones de dependencia (Sunkel 1987:45).

El enfoque centro-periferia es útil, para explicar los procesos del desarrollo capitalista en la periferia, en función de las necesidades del centro, pero subraya que la literatura expresada bajo la dependencia no ha tomado en cuenta los cambios representados y acentuados, o el grado de "transnacionalización”, subestimando sus efectos en políticas nacionales de desarrollo. No obstante, las notables tasas de crecimiento regionales, no se ha comprendido que el proceso de "innovación tecnológica", y la importancia del liderazgo y dominio del "núcleo dinámico de la expansión del capitalismo oligopólico tecnoindustrial" (Sunkel 1987:45) acentúa las desigualdades. En la región, este nuevo modelo se refleja en la nueva modalidad de consumo e importación masiva de novedosas formas que impulsan la brecha del desequilibrio externo. Una mayor concentración del ingreso y desperdicio de recursos, con el apoyo por parte del Estado a las exportaciones e infraestructura, generan una insaciable demanda de recursos para financiarlos, y el consecuente déficit del sector público. El círculo vicioso: vulnerabilidad y déficit externo, imposibilitan la "capacidad para la adaptación y creación de tecnología” (Sunkel 1987:47)

La propiedad extranjera de la mayoría de los insumos y las licencias pesan sobre la disponibilidad de divisas. En los setenta el proceso del desarrollo tomó la forma "marcadamente redistributiva, estatista y socializante" (ibid) en ciertas regiones, y en otras, fue marcadamente monetarista y neoliberal. La "crisis de la industrialización sustitutiva" de los setenta confluye con la 
gran expansión financiera internacional y la colosal liquidez ofrece una salida, parcial, en lugar de una reestructuración del aparato productivo y sus políticas. La década de 1980 presenta el colapso del ingreso de recursos externos, y los endeudamientos vigentes imponen a la región cambios en materia de política económica a partir de un vocabulario que no comprendía las especificidades de las economías en cuestión.

El capitalismo "transnacionalizado" sustenta su fuerza en la diversificación del consumo e innovación tecnológica. Las empresas "transnacionales, monopólicas" -en "competencia"-, incorporan a naciones, receptoras de sus capitales a la lógica depredadora en proceso. Los centros nacionales de toma de decisiones van perdiendo peso. Surge una segmentación tripartita, competencia oligopólica de las gigantes transnacionales, la economía de mercado tradicional, de medianos y pequeños y colateralmente la vasta "masa de la economía semicapitalista" (subordinada, marginal, informal)" (Sunkel 1987:49), y finalmente el creciente segmento de "desempleo estructural" y la economía subterránea en los países industriales" (ibid). Gobiernos y empresas transnacionales no presentan autonomía alguna debido a que son parte del "sistema único" (Sunkel 1987:50) "sistema transnacional o supranacional" lo cual exige un "enfoque conceptual más apropiado" (ibid) ante la nueva "integración financiera global de la economía" (Sunkel 1987:51).

\section{La disolución de la visión centro-periferia: sin nostalgias.}

Hemos observado la nueva hegemonía de cierta causalidad originada por el dominio del orden internacional "transnacionalizado", exigiendo un cambio de estrategia para el desarrollo y por tanto una explicación alternativa. En ese entonces, el relato de Sunkel presenta un nuevo apartado: "El desarrollo 'desde' dentro o 'hacia' dentro: la opción estratégica crítica”, donde se anuncia una lectura sui generis de Prebisch. De hecho, asume la descripción de histórica Prebisch: dos guerras mundiales y las crisis de 1930, sucesos que ofrecieron posibilidades a la periferia para fomentar el desarrollo industrial y promover "el desarrollo desde dentro". Las transformaciones y perturbaciones, durante el período de "propagación universal de la técnica", tendrían que haber generado una mutación en la estrategia de antaño:

En otras palabras -dice Sunkel- profundos cambios y perturbaciones en el sistema global permiten y requieren cambios estructurales en la periferia mediante el impulso a la industrialización que hasta entonces se había visto muy limitada. Se trataba de trasladar el impulso dinámico de desarrollo desde afuera hacia desde dentro. Este juego de palabras trata de destacar que Prebisch pone aquí el acento en una cuestión fundamental y sorprendentemente perceptiva, que constituye para el autor de este trabajo todo un redescubrimiento en sus planteamientos originales. Es bien sabido que (...) se ha hecho costumbre distinguir entre las etapas del desarrollo hacia afuera, antes de la década de los treinta, y del desarrollo hacia

18 En Sunkel (1978) se utiliza una matriz estilo Leontieff para describir los orígenes de los ingresos y grupos sociales respectivamente. 
adentro, mediante la industrialización por sustitución de importaciones, (...) El planteamiento original de Prebisch (...) distingue ambas etapas en términos de compensar el estímulo dinámico de la propagación de la técnica que provenía desde fuera, y que se había hecho insuficiente, mediante el desarrollo de dicho estímulo desde dentro. El cambio de preposición sugiere una distinción fundamental. Prebisch está pensando evidentemente en un proceso interno de industrialización capaz de generar un mecanismo de acumulación y generación de progreso técnico y mejoras de productividad como el que se constituyó a partir de la revolución industrial (...) Esta interpretación se apoya no sólo en la frase citada textualmente, sino en todo el contexto dentro del cual se formula. (...) corresponde exactamente a la forma en que Prebisch caracteriza la incorporación del Japón al proceso de 'propagación universal del progreso técnico' al señalar que dicha incorporación se da cundo ese país 'se empeña en asimilar rápidamente los modos occidentales de producción' (...) se trataría de asimilar, y no de transferir, copiar o reproducir el progreso técnico, y el acento se coloca (...) sobre los modos de producir, o sea, sobre la oferta. En contraste con lo anterior, la expresión 'desarrollo hacia dentro', en lugar de poner el acento en la acumulación, el progreso técnico y la productividad, coloca el énfasis en la demanda, en la expansión del mercado interno y en el reemplazo por producción local de los bienes previamente importados. (...) ampliación del mercado interno y en la reproducción local de los patrones de consumo, producción industrial y tecnológica de los centros, mediante el proceso de sustitución de importaciones (...) La estrategia del desarrollo industrial desde dentro tiene implicaciones muy diferentes. (...) también se traduce en una sustitución de importaciones, pero comenzando por establecer las industrias que se consideraban en ese entonces pilares fundamentales para crear lo que ahora llamaríamos un núcleo básico técnico e incremento de la productividad. (...) la industria del hierro y el acero, de la electro y metalmecánica, de la química básica, y de la infraestructura de energía transportes y comunicaciones, a partir de la utilización de recursos naturales hasta entonces desaprovechados (...). (Sunkel 1987:42).

Retrospectivamente, sabemos que el "juego de palabras" y el historial sobre la "transnacionalización", hace posible reconfigurar el estructuralismo, cuya nueva síntesis en 1991 se plantea como la "renovación del neoestructuralismo" (Sunkel 1991:31). ${ }^{19}$

Pero antes veamos la travesía teórica en cuestión. En un evento de homenaje a Raúl Prebisch, en 1987 -Prebisch fallece en 1986-, Sunkel expone su nueva síntesis de las relaciones internacionales, y las vicisitudes de la concepción centro-periferia. Entonces se generaron una serie de comentarios, los cuales lo obligan, primero a dudar de la plena comprensión por parte de los oyentes de las tesis expuestas, y ante el reiterado discernimiento, aclara que su sugerencia presupone que la perspectiva centro-periferia ya no es viable para comprender el "capitalismo transnacionalizado". Realiza tres comentarios a las intervenciones (Sunkel, 1987a), y a la "percepción en el coloquio de lo que se entiende por el "enfoque centro-periferia". El segundo y tercer comentario es muy significativo, confiesa los aspectos que supone describen el enfoque. Las dudas que confiesa Augusto

19 Tres años después, en el libro (Sunkel, 1991) en (Sunkel, 1991a) se subraya que el proceso de industrialización, no siguió "propósito preconcebido", por parte de las autoridades económicas, o "de la intelectualidad de la época" (1991a: 63), sino "precisión de las adversas circunstancias externas" (1991a: 62-3). Por otra parte, entre 1987 (Sunkel, 1987:42) y 1991 (Sunkel, 1991: 63) el "juego de palabras" (Sunkel, 1987:42), se transforma de "preposición”, a "adverbio": "el planteamiento original distinguía ambas etapas en términos de compensar el estímulo dinámico de la propagación de la técnica que provenía 'desde fuera', y que se había hecho insuficiente, mediante el desarrollo de dicho estímulo 'desde dentro'. El cambio de adverbio sugiere una distinción fundamental”' (Sunkel, 1991: 63). 
Mateus (1987), son interesantes a la luz de la respuesta de Sunkel por lo que subsecuentemente, a fines de 1988 realiza en "Institucionalismo y estructuralismo" (Sunkel, 1988), y su propuesta "desde dentro" en el libro (1991b), que de hecho anticipan algunos aspectos de la culminación teórica que discutiremos más adelante.

En el coloquio, Mateus insistía:

la referencia a la contraposición entre oferta-demanda queda un poco estrecha (...), es más autonomía frente a integración del mercado interno en el mercado mundial de forma más o menos clara. (...); hablar de desarrollo 'desde dentro' y no 'hacia dentro' supone salir de la concepción industrialista-productivista y pensar la sociedad como un todo (Mateus, 1987: 55 invertí el orden de aparición de los párrafos.)

Sunkel percibe una "sensación" de que aparentemente el enfoque fue "útil" pero ya "no lo es" (Sunkel, 1987: 296). A su vez, aclara lo que había reiterado previamente, sobre la distinción "desde dentro, no hacia adentro" (296), donde la historia del desarrollo latinoamericano, la relación centro-periferia,

tuvo una manifestación histórica de tipo fundamentalmente comercial, ha ido transformándose en formas y modalidades de relación, en que lo comercial va cediendo lugar a la articulación transnacional de los sistemas productivos y financieros, con la corporación transnacional en el rol, protagónico. Eventualmente, incluso la relación comercial se transforma (...), configu[rándose] (...) una nueva estructuración de la economía mundial, en donde diferentes partes del sistema cumplen distintas funciones, de modo que las empresas transnacionales pueden seguir acumulando y conquistando mercados. Hagamos entonces el homenaje que corresponde a Prebisch y su enfoque centro-periferia, pero enriqueciendo la descripción histórica que su caracterización inicial pretendía y tratando de entender el mundo como realmente funciona ahora. Para muchos países del Tercer Mundo el sistema centro-periferia sigue operando de aquella manera, pues siguen siendo exportadores de productos primarios e importadores de manufacturas. (...) otros han pasado a ser también exportadores industriales, pero en forma dependiente y cumpliendo una clara función del sistema global. (...) Salvo pocas excepciones (...) no han logrado trasladar el impulso dinámico de crecimiento desde fuera hacia desde dentro, como lo imaginaba Prebisch, configurándose una nueva etapa en el sistema centro-periferia. Por consiguiente, la discusión de si (...) otros países son parte del centro, de la periferia o si constituyen una semiperiferia, no me parece particularmente esclarecedora. (...) más interesante que ese ejercicio es comprender la naturaleza del sistema global contemporáneo y tratar de precisar las diferentes formas de inserción de los distintos países, en un mundo mucho más complejo y diferenciado que en el pasado (Sunkel, 1987: 296;297).

Por su parte, Di Filippo (1987) participó de dicho evento, tal vez perplejo por lo que ha escuchado (Di Filippo, 1987a), y a contrasentido, plantea que las perspectiva de Prebisch, sobre el "dinamismo autocentrado" por medio del proyecto de industrialización, está inscrito sobre dos "campos fundamentales", ambos, bajo la lógica de un desequilibrio estructural: el "del empleo" y el "comercio exterior", ámbitos en los cuales se generan los desequilibrios fundamentales de la 
economía, ya que reflejan la manera en que la heterogeneidad entre los distintos sectores generan una apropiación sesgada de los frutos del progreso técnico, tanto en el ámbito de empleo como en el de las relaciones de intercambio externo (393), dando lugar a la noción de la heterogeneidad consustancial de las economías regionales, todo lo cual explica la importancia y vigencia de las ideas de Prebisch.

Para 1988, la CEPAL y su revista, presentan tres trabajos, entre otros, que subrayan el vocabulario estructuralista a través del prefijo "neo" versus la perspectiva neoliberal: Ffrench- Davis (1988) Bitar (1988) y Rosales (1988b), quien como hemos visto anticipó la problemática de la discusión en una reseña de los textos recientes inscritos bajo el (neo) estructuralismo (Rosales, 1988a) en Pensamiento Iberoamericano.

Sunkel, a fines de 1988, amplía las ideas que habrían de conquistar un lugar importante en el libro de 1991. La propuesta de 1987, suponía "reconstruir" la teoría del desarrollo, y por lo tanto, la evolución teórica está en proceso, apoyándose en los retratos histórico-estructurales de la transnacionalización regional.

Es en su diagnóstico del pensamiento institucionalismo norteamericano y del estructuralismo, a fines de 1988, que observamos el meta-relato mediante el cual se pueden distinguir a discursos económicos "dispares" entre sí. Cabe insistir entonces, que si bien, Sunkel consintió en 1991 en sumarse a la renovación del neoestructuralismo, ${ }^{20}$ el relato y la crítica que articula dicha problemática va más allá de un simple "juego de palabras" (Sunkel, 1987:42). Desde entonces dos años han transcurrido, y los cimientos de su perspectiva no pueden ser más claros:

Un aspecto interesante y promisorio del enfoque estructuralista es el intento, en el decenio de 1980, de dar una expresión más formal y matemática a algunos de sus conceptos fundamentales (Taylor, 1979 y 1983; Jameson, 1986). Esto se ha denominado neoestructuralismo. Este interesante esfuerzo ha revitalizado al estructuralismo, pero ha tendido a concentrarse en problemas de equilibrio y ajuste a corto plazo, más que en cuestiones de desarrollo económico. (...) Lamentablemente, los escritores latinoamericanos de la tradición de estructuralismo y dependencia no han prestado bastante atención al institucionalismo" (...) El enfoque estructuralista y dependentista tiene una perspectiva mundial. (...) El institucionalismo también es, por supuesto, particularmente vigoroso en la esfera de la tecnología (...) La tecnología es absolutamente fundamental para el pensamiento institucionalista, como que es, en este enfoque, la fuerza motriz de la evolución y el cambio. (151) El cambio tecnológico se considera como un aspecto de la cultura dinámico y generador de transformaciones, derivado de la acumulación de conocimientos y alicientes transculturales; pero las pautas culturales definen, a su vez, el grado y la índole de su incorporación en el cambio cultural. Esta íntima relación de la tecnología —considerada como el desarrollo acumulativo de ideas, ins-

20 En la "Introducción” del libro (Ramos, Sunkel, 1991), escrita conjuntamente con Joseph Ramos, no se aclara quién introdujo "mi colaboración": "Contribuir a la tarea de responder a ese desafío intelectual es el factor que originó mi colaboración en esta obra. Ella se nutre de las experiencias e ideas que se vienen debatiendo en la región y se inspira en especial, pero no de manera exclusiva ni excluyente, en la vertiente del pensamiento neoestructuralista que ha emergido en la pasada década y cuyas raíces engarzan, a su vez, con el estructuralismo de las décadas precedentes" (Ramos, Sunkel, 2001:16-17). 
trumentos y destrezas - con la cultura de la que proviene, y a la que aporta su contribución, es un elemento fundamental del institucionalismo. Es un aspecto de la teoría del desarrollo muy descuidado por el estructuralismo el que ha tenido una visión más restringida de la tecnología. (152). Otra esfera en que los estructuralistas tienen mucho que aprender de los institucionalistas es su análisis amplio de las características institucionales y de la estructura y dinámica corporativas de la economía de los Estados Unidos (Sunkel, 1989: 151-152) ${ }^{21}$

Por lo tanto, la evolución de sus ideas, sus diferencias respecto la perspectiva centro-periferia y estructuralismo así como la subsunción del institucionalismo es crucial para comprender la mutación de la visión de Sunkel en 1990-91, (Sunkel, 1991), pero resta preguntarse desde donde realiza las evaluaciones de las “disparidades” de los enfoques entre sí:

quisiera esbozar una perspectiva conceptual que he encontrado útil para diferenciar la síntesis neoclásica del enfoque estructuralista, particularmente para la comprensión del proceso de desarrollo económico. Creo que ésta puede ser también una manera conveniente de examinar las diferencias entre la economía convencional y las escuelas disidentes de pensamiento económico en general, y de notar las semejanzas entre éstas -incluidos, en este caso particular, el estructuralismo y el institucionalismo. Mi propuesta consiste simplemente en distinguir entre ellas según la importancia que cada una atribuye [al stock C.M.] y los flujos en el proceso económico. Por existencias [el stock C.M.] entiendo el concepto clásico de la dotación de recursos humanos, naturales y de capital que una sociedad tiene a su disposición en un momento determinado; por flujos, las corrientes de producción, ingresos, gastos y transferencias por unidad de tiempo obtenidas de esa dotación. La economía política clásica hacía mucho hincapié en los recursos, sin descuidar los flujos derivados de ellos. La economía neoclásica convencional, el paradigma predominante, por el contrario, ha logrado eliminar de su marco teórico, de su enseñanza y de su investigación y recomendaciones de política, casi toda referencia a los recursos productivos de la sociedad, y se ha concentrado casi exclusivamente en los flujos a nivel tanto microeconómico como macroeconómico. (Sunkel, 1989: 152, subrayados del autor).

Es obvio que los aspectos relacionados con la generación de recursos o la "producción" (oferta) tendrán que observarse en términos de una "unidad de tiempo", la cual no es necesariamente homogénea, y por lo tanto la "demanda" no presentará una relación unívoca respecto la producción ("oferta"), consecuencia de asumir plenamente la perspectiva medioambiental: en otras palabras, la noción de "oferta" y "demanda" no puede explicarse bajo sus acepciones "keynesianas" (Sunkel, 1991, 1990), aspecto que tocaremos al final.

Mientras tanto, en 1989, otro volumen del Pensamiento Iberoamericano presenta, por no decir proclama, lo que sería el pensamiento de la CEPAL, con textos de Fajnzylberg y Pinto. Hoy se sabe que los textos de Fajnzylberg (Fajnzylber, 1989) y el de Pinto (1989) reflejan dos momentos "desiguales" en la pugna por restablecer lo que se entiende por neostructuralismo. Primero veamos

21 "Lo que sostiene el estructuralismo, y particularmente la reflexión sobre la dependencia, es que la índole del proceso de transferencia de tecnología ha inhibido la creación de una capacidad técnica endógena en América Latina. La construcción de una base nacional de capacidad tecnológica es ciertamente fundamental para el desarrollo, y los países de América Latina han tratado de crearla de diversas maneras. Sin embargo, hemos seguido siendo grandes consumidores" (Sunkel, 1989: 152). 
las aportaciones de Pinto y después revisamos a Fajnzylberg.

Por su parte, la propuesta de Pinto (1989) lleva un doble cometido, intenta, simultáneamente, neutralizar la postura de Sunkel, y la del propio Fajnzylber (Fajnzylber, 1989) cuyo texto aparece en el mismo volumen ("Sobre la impostergable transformación productiva de América Latina”). Sin mencionar a Sunkel, se opone de hecho a su vocabulario y acepciones. Respecto la estrategia industrializadora, a partir de la noción de los "complejos integrados" la dicotomía "hacia adentro y hacia fuera" todavía tendrían vigencia y pertinencia, y lo que estaba en juego eran los eslabonamientos entre diversos sectores, y los “complejos integrados", así como las posibilidades de sus eslabonamientos productivos horizontales o verticales:

La traducción más concreta de estas mismas o renovadas preocupaciones estaría ahora en la identificación y desarrollo de los llamados ‘complejos integrados` de producción, en los cuales 'las actividades productivas tienden a encadenarse mediante la multiplicación de las articulaciones entre actividades agrícolas o mineras, industriales o de servicios`, que pueden estar proyectadas sea al mercado interno, sea al externo o a ambos en distintas proporciones. Desde este último ángulo se sobre pasa la alternativa o dicotomía del crecimiento hacia fuera y el desarrollo hacia adentro a la que aludimos" (Pinto, 1989: 67-8).

Una política "hacia adentro" con adecuadas articulaciones "hacia fuera", estarían surtiendo idénticos efectos que los que sugieren la terminología de Sunkel con su acepción "desde dentro"; en otras palabras, la significación común de una política "hacia adentro" no debe deducirse de las políticas fomentadas por los gobiernos latinoamericanos. Como hemos mencionado antes, el historial y la defensa de la perspectiva centro-periferia, a través del proceso de deconstrucción de la narrativa neoliberal, ${ }^{22}$ es incorporada por parte de Pinto, a la discusión sobre la concepción del modelo de los "complejos integrados". Las relaciones entre estas empresas y sectores productivos -tanto internas y externas- y pueden emplearse, sin "postergar" necesariamente la tesis de Fajnzylber en torno a los "núcleos endógenos", siempre y cuando se ponderen las especificidades. Para resaltar la importancia de la indecidible situación, y por tanto la prudencia requerida, se remite a una antigua discusión entre Nurkse y Furtado: ${ }^{23}$

Otro aspecto a subrayar es la relación entre el carácter o contenido de la incorporación del progreso técnico y la heterogeneidad de nuestras estructuras productivas y sociales (...): la política al respecto no puede pasar por alto que (...) una parte significativa de la 'periferia interna' latinoamericana, de sus actividades productivas y de la población que vive de ellas, se encuentra en realidad donde -recordando una imagen ya citada de Celso Furtado- 'la mera introducción de la rueda significaría un progreso considerable'. Cámbiese a 'la rueda 'por la

22 Algo que Pinto ya había realizado años antes en 1983 (Pinto, 1983).

23 "El factor capital substituye al factor trabajo siempre que ese se justifique con una baja de costos. Siendo así, la introducción de máquinas automáticas para fabricar calzado en una comunidad primitiva significará ciertamente no en una baja sino una gran alza de costos (...) para que se logre un sensible aumento de productividad en un país subdesarrollado no es necesario introducir los equipos más modernos. En muchas regiones del Brasil, la introducción de la rueda significaría un progreso considerable (subrayado de A.P.). La simple apertura de un camino puede determinar un fuerte aumento de la productividad" (Pinto, 1989: 78-9). Véase, Mallorquin, 2013a; 2013 b. 
multiplicidad de medios e instrumentos básicos capaces de elevar la productividad y niveles de vida en nuestros 'hinterlands ' y se convendrá en la gran potencialidad de tal perspectiva (...) no prosperará espontáneamente o por las guías del mercado si no tiene el respaldo de una conducta definida y comprensiva de la política general (83) (...) insistimos, no se contradice con la búsqueda insistente de la excelencia tecnológica y con el hecho de que a veces no hay alternativa que la vigente en los países generadores de la misma. (Pinto, 1989: 84).

No olvida que la idea de los "complejos integrados" puede observarse en términos de la perspectiva cepalina ${ }^{24}$ :

En primer lugar, la elevación del grado de procesamiento y diseño de consumo final que hacen uso intensivo de los recursos disponibles en la región (agricultura, pesca, forestales, minería, energía) que, además de responder a exigencias locales, cumplen con las especificaciones requeridas por el mercado internacional; en segundo lugar, el fomento selectivo de aquellas actividades productivas que satisfagan dos requisitos simultáneamente; ser portadoras de progreso técnico y constituir el sustento principal de la articulación intersectorial (bienes de capital e industria química); y tercero, la incorporación realista de las denominadas tecnologías de 'punta` (que incluyen las tecnologías de información, nuevos materiales y biotecnología (Pinto, 1989: 68).

La reflexión sobre el patrón del desarrollo e "industrialización” a seguir, aunque transitan paralelamente no son lo mismo, explica tempranamente, para fines de los años setenta, la aparición de la noción de "estilo de desarrollo" tanto en Sunkel y otros en la CEPAL.

Por su parte, Fajnzylberg asocia la reflexión en torno al "casillero vacío" (“crecimiento-equidad"), así como los aspectos asimétricos de poder regionales, en la construcción de los "núcleos endógenos", interponiendo aspectos institucionales que van más allá de "costos comparativos", para decirlo de alguna manera, de lo contario su planteamiento sería insostenible teóricamente: exige el ensamble conceptual que haga posible proyectar las articulaciones entre los "agentes" y las "tradiciones culturales"25 ("sistemas productivos, esquemas institucionales y organismos sociales"), o como lo dice el propio Fajnzylberg:

la experiencia internacional enseña inequívocamente la lección del pluralismo institucional: se observan las más variadas configuraciones de agentes económicos en las economías de mercado (Fajnzylberg, 1989, en Torres, 2006: 110) (...). Lo anterior no excluye la contribución potencial, ni de los rubros de escaso contenido técnico, ni de aquellos que se originan en empresas extranjeras, pero enfatiza la relevancia de la relación entre sectores productivos,

24“Dr. Prebisch" (Pinto,1989: 77) y/o “maestro Prebisch" (Pinto,1989: 78).

25"Avanzar en una dirección diferente implica introducir la necesaria distinción entre: i) las relaciones de poder entre el polo industrial y el agrícola; ii) las relaciones técnicas entre ambos polos, y iii) las vinculaciones económicas, todas ellas condicionadas además por la especificidad de los rubros en cuestión." (276) "El rasgo central de la 'nueva industrialización' es la articulación en torno a un 'núcleo endógeno' y esto debe reflejarse diáfanamente en la base social de sustentación. El centro de gravedad de esta debe localizarse en movimientos, agrupaciones o partidos capaces de asumir un compromiso estratégico con la dignidad nacional, la superación de las carencias sociales heredadas, el desarrollo de la potencialidad creativa de la población y la soberanía en el uso de sus recursos naturales. (291) Al caracterizar la industrialización latinoamericana ha quedado en evidencia, como uno de sus aspectos característicos, la precariedad del liderazgo ejercido por el empresariado industrial nacional, sector social que en los países de capitalismo avanzado desempeñara exitosamente esa función." (291) (Fajnzylberg, 1989, en Torres, 2006: 276 y 291. 
empresas y tipos de mercados, en la que resulta fundamental profundizar para avanzar en la comprensión del proceso de innovación tecnológica. El hecho de que la macroeconomía convencional haga abstracción de esta vinculación (sectores empresas, mercados) porque no es relevante para el objetivo de su análisis inhibe su capacidad de `capturar`el núcleo central de la dinámica del progreso técnico (Fajnzylberg, 1989, en Torres, 2006: 92, subrayados del autor) (...) En el mercado internacional compiten no solamente empresas, sino que se conforman sistemas productivos, esquemas institucionales y organismos sociales en los que la empresa constituye un elemento importante, pero integrado en una red de vinculaciones con el sistema educativo, la infraestructura tecnológica, las relaciones gerencial-laboral, público-privado y el sistema financiero. En dicho contexto, las empresas de mayor tamaño, que en general tienen acceso privilegiado a los organismos públicos que definen políticas, desempeñan una función de orientación y, en muchos casos, de conducción en el funcionamiento de estas relaciones sistémicas (Fajnzylberg, 1989, en Torres, 2006: 103-4, últimos subrayados son míos).

Sin duda el historiador de la competitividad - productividad- "espuria" del proceso de "industrial" latinoamericano niega ajustes automáticos de la transformación industrial exclusivamente hacia ciertos sectores "capital intensivos" ${ }^{26}$ como se indicó en la cita, aunque tampoco reniega de ella sistemáticamente.

En la CEPAL, en 1990, se publica, Transformación productiva con equidad (CEPAL, 1990), el texto marca el dominio de las apreciaciones sobre lo que se entiende por neoestructuralismo o sus "equívocos", especialmente si observamos la obra de Sunkel. En la Revista de la CEPAL, aparece "Neoestructuralismo versus neoliberalismo en los años noventa", de la autoría de Sunkel y Zuleta (1990), lo cual es una síntesis introductoria del libro El desarrollo desde dentro....

26 'Para avanzar en la comprensión de esta 'causación virtuosa acumulativa' que vincula crecimiento-progreso técnico e internacionalización, es útil concentrar la atención en el sector de producción de bienes de capital. Su magnitud y estructura interna constituyen un factor explicativo importante para el análisis de la dinámica industrial; en su condición de portador material de progreso técnico, ejerce influencia en las modificaciones que experimenta la productividad de la mano de obra y de la inversión y, en consecuencia, de la competitividad internacional de las economías nacionales. En el funcionamiento del sector productor de bienes de capital, ejercen influencia factores institucionales tales como la relación sector público sector privado y la internacionalización del sector industrial. (166) (...) El ritmo de crecimiento de la demanda de bienes de capital está determinado por el crecimiento de la inversión, su estructura sectorial y por la proporción de bienes de capital incluidos en esa inversión sectorial. Se comprueba empíricamente, en las últimas décadas, que la demanda de bienes de capital crece más rápidamente que la producción industrial y, por consiguiente, que el producto nacional bruto. Esto se vincula al crecimiento relativamente más rápido de la inversión que del producto nacional, a la naturaleza del progreso técnico caracterizado por una creciente intensidad de capital en relación con la mano de obra, a la modificación de la estructura sectorial en favor de actividades caracterizadas por una mayor relación capital-producto y al incremento de la proporción de bienes de capital contenido en la inversión, fenómeno este último vinculado también a la modalidad específica que asume el progreso técnico.” (Fajnzylberg, 1989, en Torres, 2006: 166-167).

27 "En consecuencia, con la referencia al sector de bienes de capital se busca poner de relieve la naturaleza y complejidad de las decisiones que es preciso adoptar para impulsar una estrategia industrial articulada en torno a un núcleo endógeno. Es probable, por ejemplo, que, en determinada etapa, la tarea de modificar las relaciones industria-agricultura, tenga una gravitación significativamente mayor, pero tarde o temprano será necesario abordar el tema de los bienes de capital, pues constituye un componente necesario del núcleo endógeno. Precisamente porque el tema de bienes de capital es solo uno de los componentes, aunque desempeña una función primordial de articulación, el análisis de los obstáculos que es preciso vencer en esa área ilustra la magnitud de la tarea asociada al diseño e instrumentación de una concepción (...). El sector de bienes de capital presenta ciertas características específicas que lo distinguen de otros sectores industriales y que exigen que el contenido de un programa de desarrollo que contribuya a expandir eficientemente su producción, tenga que trascender la simple enumeración de proyectos independientes." (Fajnzylberg, 1989, en Torres, 2006: 263-264). 
(Sunkel, 1991). Relatos recientes, hacen de dicha fecha un parte aguas, para efectos tanto teóricos como institucionales, ambigüedad congénita a instituciones y sus "empleados" cuya "autoría" de sus palabras no significa "propiedad' de las mismas. Por ejemplo, Guillen habla de "nueva CEPAL" en lugar de neoestructuralismo (Guillen, 2007:313).

Sin embargo, la participación de Sunkel en dicha elaboración del neoestructuralismo en 1990 debe ser relevante para los historiadores de las ideas debido a que sus ideas para ese entonces ya habían trascendido la perspectiva centro-periferia (suponiendo que estemos de acuerdo sobre lo que se entiende por ella), y además porque las recientes "referencias" a su trabajo y al capítulo incluido ("Del desarrollo hacia adentro al desarrollo desde dentro") en el libro que coordina en 1991, revelan una desatención inmerecida.

Para 1991 Sunkel ha incorporado la descripción de los distintos diagnósticos teóricos en torno a la región y

pareciera existir consenso en que la estrategia de desarrollo estructuralista estuvo muy sesgada a la industrialización por sustitución de importaciones. Sin embargo, pese a que este juicio crítico parece básicamente correcto, desvía la atención a lo accesorio, descuidando lo central. Lo fundamental es que la estrategia de industrialización y de desarrollo del pasado estuvo centrada en la expansión del mercado interno, en el fomento de la producción interna de bienes industriales de consumo previamente importados. (...) desmesurado proteccionismo (...) fomento del consumo mediante subsidios, precios controlados y créditos al consumo (...), inversiones destinadas de preferencia hacia la expansión del mercado de bienes de consumo duraderos imitativos (1991a: 44-45).

La descripción histórica del proceso en 1987, que explica la debacle de la década de 1980, se repite para la versión en del año 1991, pero en ésta ocasión, una vez descrita la evolución de aspectos sectoriales y macroeconómicos, la narrativa dialoga con la única "propuesta actualmente" (1991a: 61) disponible por parte de los "organismos Internacionales" -el discurso neoliberal- pregonado por doquier: reducción de la participación del estado; mayor presencia del capital privado y del "mercado"; "mayor apertura externa" de las economías. Aquí Sunkel distingue entre aspectos meramente ideológicos de la propuesta neoliberal de privatizar por privatizar, y aquellos que reflejan una racionalización del proceso de transformación económica considerando prudentemente las alternativas.

La propuesta "desde dentro" requería una estrategia de transformación tecnológica más allá de la simple exigencia por una mayor privatización y reducir el gasto público y cuentas externas "equilibradas", igualmente exigía la creación de condiciones que generaran un "núcleo endógeno de dinamización tecnológica" "un esfuerzo creativo interno por configurar una estructura productiva que sea funcional a las carencias y potencialidades específicas nacionales' (Sunkel,1991a: 64).

O sea, para 1990-91, Sunkel, hace expresa referencia a las ideas de "Fajnzylber (1983)" (Sunkel,1991a: 64), se requiere de un, 
'esfuerzo creativo interno por configurar una estructura productiva que sea funcional a las carencias y potencialidades específicas nacionales'. (...) se comienza por establecer las industrias consideradas pilares fundamentales para crear lo que hoy llamaríamos un núcleo endógeno básico para el proceso de industrialización (...). De este impulso creador inicial la industria del hierro y del acero surgen la electro y metalmecánica, la química básica y la infraestructura de energía, transportes y comunicaciones a partir de la utilización de recursos naturales (...) y de la articulación del territorio y del mercado nacional (...) (Sunkel, 1991: 64) El enlace dinámico no se da, prioritaria ni principalmente, desde la demanda final hacia los insumos y los bienes de capital y la tecnología, sino más bien y de manera selectiva desde éstos últimos elementos hacia la captación de las demandas internas y externas consideradas fundamentales (Sunkel, 1991a: 64;65) ${ }^{28}$

La transición productiva, los acertijos en torno a las prácticas, así como su teorización, sugiere fusiones conceptuales a partir del vocabulario de Fajnzylber. Pero en Sunkel, como ya se ha mencionado, dicha afiliación, si es que existe, proviene de otra tradición.

Las apreciaciones pasadas y presentes sobre el neoestructuralismo perdieron de vista esta singularidad del vocabulario, que según Sunkel, hace posible diferenciar a dispares discursos económicos entre sí, que a su vez genera la manera para reflexionar en torno a la relación del corto y largo plazo, (Sunkel 1991a), donde el uso de las categorías keynesianas si es que no impertinentes, requieren una "adecuación" conceptual específica, lo mismo, por parte de aquellos que entienden su postura con las tesis del crecimiento por el lado de la "oferta" (Guillen, 2007: 312-13).

Como veremos a continuación esta disyuntiva se intenta resolver de otra manera; aunque es cierto que el enfoque estructuralista como hemos señalado, en ese entonces concedió ${ }^{30}$ bastante al asumir las supuestas "deficiencias" del estructuralismo respecto la resolución de los desequilibrios

28 Fajnzylberg ya lo había dicho en 1983: "La opción real es muy diferente: constituir un núcleo endógeno capaz de incorporarse en el proceso de dinamización tecnológica, que es la condición necesaria para penetrar y mantenerse en el mercado internacional, en vez de delegar en agentes externos la responsabilidad de definir la estructura productiva presente y futura del país. (241) (...) Por esta última vía solo se exportarán recursos naturales, mientras exista la demanda o hasta que se agoten, productos manufacturados que requieren la existencia de condiciones sociales que permitan salarios excepcionalmente bajos, circunstancia inexorablemente efímera o, por último, aquellos productos manufacturados ubicados en la fase tecnológica senil, los que, por definición, presentan magras perspectivas de crecimiento. (241) (...) Se trata de que los países de América Latina emerjan de este período de transición con un "núcleo endógeno" articulado y tecnológicamente fortalecido, con capacidad para penetrar sólidamente en los mercados internacionales, los que con posterioridad a esta fase de transición, recuperarán nuevamente su dinamismo" (242) (...) "En efecto, cuando este proceso se desarrolla en Estados Unidos, la 'destrucción' de los bienes existentes y los correspondientes efectos sobre el uso de recursos productivos, se ve neutralizado por la 'creación' de nuevos bienes (242) (...) Es decir, se desarrolla plenamente el proceso de 'destrucción creadora' descrito por Schumpeter. Las filiales de estas corporaciones establecidas en América Latina también incorporan nuevos productos, procesos, equipos, técnica publicitaria; pero la diferencia radica obviamente en el hecho de que, con escasas excepciones, que no necesariamente se refieren a la publicidad, la fase 'creadora' de estas actividades no se realiza localmente" (Fajnzylberg, 1975, en Torres, 2006: 131); (Fajnzylberg, 1983, en Torres, 2006: 241-42).

29 Guillen resalta: "Por si lo anterior fuera poco, su análisis de la demanda está menos presente que en el discurso de sus ancestros, ya que consideran que los problemas de América Latina son sobre todo de oferta. Al respecto, Sunkel y Zuleta no tienen empacho en señalar que el esfuerzo critico debe realizarse del lado de la oferta (acumulación, calidad, flexibilidad, combinación eficiente ele los recursos productivos y predican -como los neoliberales- la disciplina social, la frugalidad en el consumo público y privado y el aliento al ahorro nacional" (Guillen, 2007: 312). Por su parte, (Ocampo et. al, 2009), ofrecen una importante discusión entre el crecimiento impulsado por la demanda de cuño keynesiano a través de la obra de Kaldor, vis a vis, la del lado de la "oferta" ("mainstream") cuya explicación no es determinante: "the supply-side interpretation is not compelling” (Ocampo, et. Al: 2009: 146). 
“macroeconómicos" (Lustig, 1988: 47-48, Bitar,1988: 47; French Davis, 1988: 38, Rosales, 1988a y 1988b), debido al olvido de aspectos de corto plazo.

Sunkel, además y casi de manera ortogonal, ofrece la distinción entre el "stock" y los "flujos" a corto y largo plazo, rememorando la perspectiva en torno al medio ambiente ${ }^{31}$ y sus condiciones de existencia:

Para poder abordar el problema de vincular el corto con el largo plazo, los factores estructurales con los de funcionamiento de la economía y los aspectos socioculturales y políticos de una manera positiva es preciso superar los enfoques unidireccionales y parciales que prevalecen (...) esta compleja tarea de articulación podría consistir en distinguir por una parte, entre flujos de corto plazo, generalmente anuales y por la otra los patrimonios activos, acervos o stocks adquiridos y acumulados en el largo plazo (Sunkel, 1991a: 67 subrayados míos).

Dedica especificaciones en cada caso para reflexionar las relaciones entre los patrimonios sociocultural, el natural, y del capital y que son en última instancia "versiones ampliadas de los tres factores clásicos de la producción: trabajo, tierra y capital” (Sunkel, 1991a: 67).

Señalemos un ejemplo. Aquí nos sugiere reflexionar la vinculación entre "lo sociocultural y político con lo espacial-ambiental" y las relaciones entre flujos de "mediano y largo" y "los anuales":

Estos se refieren fundamentalmente a los equilibrios macroeconómicos de corto plazo, y su foco son los equilibrios fiscales, monetarios, externos, del empleo y de los ingresos, y sus implicaciones y condicionantes sociopolíticos. Así (...), el grave desequilibrio externo negativo en materia de flujos de ingresos y salidas limita gravemente las importaciones, provocando una considerable subutilización del potencial acumulado en cuanto a patrimonio sociocultural, humano, natural y de capacidad productiva (Sunkel, 1991a: 67-8).

A lo largo del argumento, se amplía la distancia y diferencia entre la terminología conceptual suya y la que reina en las diferentes participaciones del libro (Sunkel, 1991), con la excepción de la de N. Gligo quien escribe el capítulo en torno al medio ambiente (Gligo, 1991, en Sunkel 1991) que a su vez a compartido publicaciones con Sunkel. El resto de los autores estarían haciendo referencia al estructuralismo difundido, ausente en la narrativa de Sunkel.

Se debe subrayar que el vocabulario del relato es distinto al de 1987: "en este nuevo planteamiento se parte de las potencialidades propias y se postula que cada país puede y debe buscar nuevas maneras de inserción en un contexto internacional difícil pero no impenetrable (Sunkel, 1991c: 10-11). Igualmente, la

30 Comparto en parte la crítica de Guillen (Guillen, 2007), porque creo que las concesiones teóricas no se deben necesariamente a cambios en los liderazgos de las "instituciones" (CEPAL), ya que se trata de "agencias" o entidades cuya unidad no está predeterminada. Por otra parte, creo que nadie en su sano juicio podría comprender o explicar la manera en que instalan líneas de trabajo y directrices; alguna vez escuche decir a un funcionario de la CEPAL, que se debe pensar en términos de equipos de conveniencia, amistades, concentrados en torno a un jefe "feudal". Por ello la burocracia en su versión "racional" (M. Weber) que supone que los funcionarios reciben prebendas diferenciadas o de distinta naturaleza no es el modelo apropiado, aunque útil para pensar la manera en que acopla la explicación de las gratificaciones por rango, que cada funcionario conoce anticipadamente, dadas las reglas de las instituciones de la familia de las Naciones Unidas. No obstante lo anterior, véase el admirable esfuerzo por parte de Meireles (2016) y Hodara (1987).

31 (Sunkel 1980, 1981, 1987), para más detalles, desde otro ángulo, Mallorquin, 2014; 2014a. 
postura y suerte del neoestructuralismo en 1991, tanto la significación que Sunkel otorga al mismo como la de otros no estaba confirmada. Pero, para 1991, había reconstruido su perspectiva de las políticas económicas en la región y la razón principal de sus vicisitudes:

No se trata en realidad de criticar sólo aspectos parciales de políticas económicas como la tarifa arancelaria y el tipo de cambio o los precios controlados. Es un síndrome derivado de una estrategia nacional industrialista-consumista-populista que surge como respuesta a la presión de experiencias históricas y circunstancias externas contemporáneas desfavorables, más que por una voluntad expresa de las autoridades económicas, en las que posteriormente se persiste porque daba buenos dividendos. Entre estas experiencias históricas destacan los ya señalados y bien conocidos efectos devastadores de la Gran Depresión de los años treinta y las grandes dificultades económicas ocasionadas por la Segunda Guerra Mundial. (...) El gran auge del comercio internacional (...) comenzó en la década de los cincuentas obedece en lo fundamental al restablecimiento del comercio entre los Estados Unidos y las economías europeas y entre estas últimas y sus colonias (...) y de una fuerte discriminación contra las exportaciones latinoamericanas (Sunkel 1991a: 45, subrayados míos).

Cuando decae el proceso de industrialización en los años sesenta- según Sunkel- no se realizó una "profunda" reconsideración de las políticas para conquistar mercados mundiales lo cual implicaba:

exigencias importantes en materia de creación de capacitación de innovación y adaptación tecnológica, de reasignación de inversiones, de reorientación del crédito del fomento del consumo al fomento de las exportaciones y con consecuencias muy graves en términos de relaciones intersectoriales (...) y otros instrumentos de política económica (Sunkel 1991a: 47).

Y como se mencionó antes, el diagnóstico de Sunkel de 1987, sobre la década de los años setenta, la “inflación” generada por la creación de dólares, debido a la crisis energética y el financiamiento externo, con reglas distintas a las que generó la organización de Bretton Woods, originaron el olvido de los "problemas". Ante la "permisibilidad financiera internacional" (Sunkel 1991a: 47) 32 persistieron las políticas "expansionistas" y de endeudamiento sin realizar transformaciones estructurales ("urgentes rectificaciones" Sunkel 1991a: 57). Y de hecho Sunkel (1991a: 47, a nota a pie de página) se remonta a su ensayo de 1967 (Sunkel, 1968) reiterando la disyuntiva de "exportar o morir".

A partir de los primeros años de la década de 1980, la región presenta una amplia "demanda democratizadora" que se complica con la crisis de la deuda externa. Esa problemática política e institucional se expresa en la desaparición de dictaduras militares en varios países, con la de Pinochet en 1990. Se revalorizan-dice Sunkel-, los discursos y las fuerzas sociales integrándose al "juego democrático", y sus respectivas transiciones bajo estructuras e institucionales "transnacionalizadas" y las comunidades o "sectores integrados y desintegrados" presentes en las sociedades latinoamericanas.

32 La "mayoría de los países - dice Sunkel-, prefirió eludir el necesario e inevitable ajuste restructurador de sus economías y muchos se embarcaron en un proceso de endeudamiento externo que llegó al paroxismo a comienzos de la década de los ochenta" (Sunkel 1991a: 57). 
Dicho contexto, dificulta, si es que no imposibilita, la reestructuración y transformación productiva sin asumir los aspectos negativos-recesivos. ${ }^{33}$ Se negaban todo tipo de apoyo externo para la financiación, mientras se imponía en la región el síndrome del "Consenso de Washington", bajo sus diversas modalidades (Hernandez en Barcena, Prado, 2015: 349).

Se ha extraviado, en recientes interpretaciones del pensamiento latinoamericano, por ejemplo (Neoestructuralismo y corrientes heterodoxas en América Latina y el Caribe a inicios del siglo XXI) ${ }^{34}$ la presencia del medio ambiente que se supone en la postura del libro Desde dentro... (Sunkel, 1991a).

Por una parte, la estrategia de desarrollo "nacional y regional" verdadera tendrá que "basarse primordialmente en la transformación de los recursos naturales" (Sunkel 1991a:65) y si logra salir de la crisis de la deuda, la transición hacia el desarrollo, habiendo superado la etapa recesiva, exigirá cuanto "antes un ajuste "expansivo", democrático y sostenible, superando:

la etapa de desarrollo hacia adentro y las experiencias más unilaterales de crecimiento hacia fuera para encaminarse hacia una futura estrategia de desarrollo e industrialización 'desde dentro' portadora de un dinámico proceso de acumulación, innovación y aumentos de productividad (Sunkel, 1991a: 65).

Supone inicialmente una política restrictiva, "selectiva de la demanda", con una de igual proporción por parte del lado de la oferta, pero dicha política recesiva no debe ser producto de las fuerzas ciegas del mercado, sino utilizando la "capacidad movilizadora" y "concentradora" de Estado (Sunkel 1991a: 69). Por lo tanto, el uso adecuado de los patrimonios ("stocks") acumulados, tanto el "socio cultural" como el del capital. La reactivación, se decía, deben concentrarse en tres ámbitos, gasto social, de empleo informal y mediana empresas.

Las reformas sociales pueden generar el uso de recursos acumulados, en el sentido de que se concentren en sectores "comerciables, particularmente exportables y de consumo básico, con mayor encadenamiento empleo-producto" (Sunkel 1991a: 72, subrayados míos).

Pero por otra parte, la transformación del "ambiente natural" geográfico debe realizarse a través de políticas de investigación científica con una perspectiva a mejorar la oferta ambiental adecuada, y que rompa con las tradiciones imitativas tradicionales hasta entonces.

La utilización de los "patrimonios acumulados", empieza eludiendo también la tradición administrativa "sectorial del estado" (agricultura, minería, energía transportes, etcétera) (Sunkel 1991a:73) para pensar en términos “espacial-regional” (Ibid.). Buscándose sostenibilidad, rentabilidad y perdurabilidad a largo plazo

33 "En ambos frentes, privado y público, se ha actuado entones con el objetivo de reducir los gastos y generar un excedente de ahorro interno necesario para compensar las remesas al exterior, pero el carácter por sí mismo recesivo de todas las medidas aplicadas torna muy difícil conseguir un aumento en los ahorros; en consecuencia el grueso del ajuste se ha traducido también en na reducción de la inversión, opción que compromete de manera alarmante la capacidad futura de crecer $(. .$.$) con un sesgo abruptamente regresivo, imponiendo casi todo el peso de este drástico proceso de ajuste y$ restructuración en los sectores medios y las clases populares"(Sunkel 1991: 58).

34 La excepción es el trabajo de Katz. 
del medio ambiente, generando economías positivas externas en el espacio socio-económico, mediante la incorporación de diversas perspectivas y tecnología, sistemas productivos integrados, tecnologías combinadas, y ecodesarrollo, supone una crítica al "estilo de crecimiento" (Sunkel 1991a: 74). La orientación debe plantearse metas que incorporen el uso de los recursos no utilizados, con perspectivas de sectores culturales cuyos conocimientos pueden articularse a un nuevo "estilo de crecimiento".

Dicho plano "macroeconómico", no es "automático", debe ser producto de la reactivación de los sectores antes mencionados, ordenamiento del proceso laboral y sus vinculaciones para corregir la "heterogeneidad" estructural:

Se trata en su mayoría de los casos de actividades de consumo colectivo o infraestructura productiva que no (...) interesan a la actividad privada (...) de obras y actividades que recaen regularmente en la esfera de las responsabilidades del sector público (Sunkel 1991a:74).

Esa estrategia tendrá que tomar en cuenta las particularidades locales, participación de las comunidades, y sistemas más democráticos creando programas que potencialmente se conviertan en "permanente".

El reajuste macroeconómico, implica:

orientaciones en materia tecnológica y de gestión de recursos. Es preciso limitar severa y selectivamente, salvo casos muy justificados, todo tipo de demanda suntuaria que implique directa o indirectamente un elevado componente of importaciones (....) promoviendo su reemplazo por bienes y servicios, tecnologías y diseños que se apoyen en la utilización de recursos materiales y humanos nacionales y locales-, y destinados de manera especial a satisfacer necesidades fundamentales. Sin perjuicio de que en algunas esferas y sectores, particularmente en materia de exportaciones, sea necesario emplear tecnologías avanzadas y capital-intensivas (1991a:75 subrayados míos).

Las implicaciones de políticas a corto o largo plazo no son oposiciones infranqueables, tomando en cuenta que la problemática de sustentabilidad de los recursos-stocks a relacionarse con la visión macroeconómica estatal, debe acoplar los agentes de corto plazo (ministerios, bancos) y los de largo plazo, organismos regionales, sectoriales, sin olvidar que la problemática es un desarrollo sostenido, sustentado, lo cual exige una articulación de las "metas socioculturales" a nivel internacional

Como hemos visto el aspecto "macroeconómico" y las recíprocas interrelaciones entre la "demanda" y la "oferta" suponen mecanismos que superan los cálculos de la valoración mercantil monetaria, lo cual implica que las categorías tanto de las técnicas y su localización geográfica para estimar la "productividad" potencial y, así como la de las metas de los proyectos y sus costos monetarios de los proyectos hagan referencia a un ámbito político indecidible, es decir, no se resuelve independientemente de los agentes involucrados, ni en los ministerios de hacienda. De todas maneras, la apertura hacia el pensamiento institucionalista norteamericano clásico y cierto vocabulario en torno a los "stocks" y "flujos" referentes al medio ambiente, (Sunkel 1980; 1981; 1987) hace relevante la propuesta, la cual no debe confundirse con las acepciones keynesianas sobre la inexorable lógica de la "demanda" e "inversión". Como vimos, recupera una larga tradición dentro 
del estructuralismo que busca ubicar el apoyo a estrategias productivas cuya "demanda" obedece a cierto segmento de la población.

\section{$\rightarrow$ 5. "El pensamiento latinoamericano: deudas, saldos y el neoestructuralismo.}

Sin embargo, la propia noción de heterogeneidad y desigualdades-polarizaciones que observa la imagen "transnacionalizada" de nuestras economías descrita por Sunkel en gran parte de sus escritos, no están en contraposición, necesariamente con la recuperación del pensamiento de Prebisch. No obstante, la tarea de Sunkel en haber avanzado durante muchos años, insistentemente, el estudio de la radiografía conceptual de la "transnacionalización", cuyo anverso es la "financiarización global” de hoy, ante dependendistas, marxistas y estructuralistas, es un hito por sí mismo.

La pugna por abrir los mercados latinoamericanos al capital financiero siempre fue un aspecto codiciado por los "centros" y sus instituciones. La sumisión de los gobiernos de la región, sin planteamientos alternativos, como decía Prebisch, hizo que se los impongan "desde fuera". De todos modos, no hubo suficientes reparos en materia de políticas para cuestionar la idea de que el capital foráneo sería necesariamente la fuente principal para la generación del "núcleo endógeno tecnológico" y actualmente presenciamos discusiones en torno a proyectos de "innovación" gubernamentales y disyuntivas entre "importar tecnología" o generarlas internamente, que ya se habían realizado en los primeros años de la década de 1950. No se trataba sencillamente de costos comparativos, o "precios correctos", lo cual suponía que los antagonismos entre unidades productivas y la mano de obra generarían la trayectoria a seguir. Se hizo mucho hincapié en escuchar a los "expertos" en tecnología y paralelamente, examinar los presupuestos y las "proyecciones" "micro" y "macro". La CEPAL (Prebisch, 1950 y 1952), no participó en las discusiones de Cambridge sobre el capital ("reswitching"), habiendo anticipado que el establecimiento de los precios (comparativos), y los antagonismos correspondientes, son los factores que guían el proceso de la inversión y trayectoria tecnológica. Más recientemente, desde otro vocabulario y ángulo de mirada, véase Nadal (2004:108-109). La posibilidad de experimentar entre los distintos cuadrantes de un espacio cartesiano sobre las trayectorias tecnológicas alternativas, no es idéntico al cálculo político de deducción sobre los "precios" y costos a corto y largo plazo. Intentar eludir la noción de la "ganancia", lugar donde se presentan los antagonismos entre distintas unidades productivas, es olvidar una de las mejores enseñanzas de Prebisch. (Mallorquin, 2006; 2015).

Sunkel ha dicho que "el liberalismo y el estructuralismo y sus correspondientes versiones neos conciben y explican de modo muy diferente el comportamiento del individuo"' (Sunkel y Zuleta1990: 48-49), aspecto al cual hay que retornar tomando en cuenta el aspecto asimétrico de poder entre los agentes y las fuerzas políticas (Sunkel, 2006), subrayado en su libro El subdesarrollo latinoamericano y la teoría del desarrollo. Es interesante rescatar que esa reflexión forma parte del primer capítulo del libro de Ocampo et al., (2009).

Por ello, Prebisch no rehúye a la discusión entre el socialismo y liberalismo y la necesidad de fusionarlos en Capitalismo Periférico (1981), pero en los primeros años de la década de 1980, la forma que 
toman sus recuentos, y la manera de subrayar la singularidad de su pensamiento y las ideas practicadas en la CEPAL, ${ }^{35}$ o respecto otras corrientes teóricas -talante consustancial a su persona-, dio la impresión que se estaba retractando. Por otra parte, no ayudaron tampoco ciertas reconstrucciones de la tradición estructuralista que resaltaban su insensata complicidad con la ejecución de políticas que aparentaban blindar a la economía de la "competencia" internacional.

Sin embargo, aunque parezca paradójico, Prebisch quien nunca se consideró estructuralista, en contraste con Furtado (Mallorquin, 2013), fue precisamente durante esos años cuando acuñó sin ambages el vocabulario estructuralista a través de las nociones de "heterogeneidad", "competencia regresiva" y "el excedente", mediante los cuales explicaba el mecanismo de la apropiación de los frutos del progreso técnico por ciertos agentes. Pero para entonces la sumisión de los gobiernos era un hecho consumado y la lucha de sus últimos años la libró enfrentando al movimiento neoliberal triunfante, que para fines de 1989 hacía alardes con el inicio del declive y de la historia de un espectro que desafortunadamente muchos defendieron por "socialista".

Para concluir: el pensamiento latinoamericano presenta, para fines de 1949, una inflexión pronunciada "derivada" de la creación de la CEPAL, y el liderazgo de Prebisch, es una de sus figuras centrales, pero su asunción opacó los esfuerzos teóricos previos de Mariátegui, Haya de la Torre, Sergio Bagú, entre otros, en dos aspectos que hoy conforman el vocabulario cotidiano: la construcción de un vocabulario teórico regional propio, y simultáneamente, descolonizar a las ciencias sociales. Las ideas que hemos rescatado de Sunkel van en ese mismo sentido.

35 Por ejemplo: "No soy la imagen viva de la CEPAL (...) estoy muy cerca (...) La CEPAL jamás ha propuesto un sistema (Prebisch, 1983: 49). 


\section{Bibliografía y referencias documentales}

Ackerman, F., Nadal, A., (2004), The Flawed Foundations of General Equilibrium: Critical Essays on Economic Theory, Routledge, London New York.

Bárcena, Alicia; Prado, Antonio. Neoestructuralismo y corrientes heterodoxas en América Latina y el Caribe a inicios del siglo XXI, Santiago de Chile: CEPAL, 2015.

Bielschovsky, R. (2009), "Sesenta años de la CEPAL: estructuralismo y neoestructuralismo", Revista de la CEPAL, N 97, Santiago de Chile.

Bitar, S. (1988): Neoliberalismo versus neoestructuralismo en América Latina, Revista de la CEPAI., No 34, Santiago de Chile.

Bulmer-Thomas V., (2011), La historia económica de América Latina desde la Independencia, México: FCE.

CEPAL, (1990), Transformación productiva con equidad (2010). Santiago de Chile.

Connell, Raewyn, Dados, Nour (2014), "Where in the World Does Neoliberalism Come From? The Market Agenda in Southern Perspective", Theory and Society, (43) 2, 117-138.

Cypher J. M., (1988), "Slow Death of the Washington Consensus on Latin America", Latin American Perspectives, 25 (6): 47-51

Ffrench-Davis, R. (1988), “Esbozo de un planteamiento neoestructuralista”, Revista de la CEPAL No 34, Santiago de Chile,

-,(1991), "Formación de capital y marco macroeconómico: bases para un enfoque neo estructuralista", El desarrollo desde dentro: un enfoque neoestructuralista para América Latina, Osvaldo Sunkel (comp.), Lecturas, No 71, México, D.F., Fondo de Cultura Económica.

Di Filippo, A., (1987), "El deterioro de los términos de intercambio treinta cinco años después”, en el Coloquio de Madrid, "El Sistema Centro- Periferia en Transformación". Pensamiento Iberoamericano, (Madrid) (11): 357-383; Enero-Junio.

-, (1987a), Intervenciones en el Coloquio de Madrid, “El Sistema Centro- Periferia en Transformación”. Pensamiento Iberoamericano (Madrid) (11): 392-397. Enero-Junio.

Fajnzylber, Fernando -, (1983), La industrialización trunca de América Latina, México, D.F., Editorial Nueva Imagen, S.A

-, "Sobre la impostergable transformación productiva de América Latina" Pensamiento Iberoamericano (Madrid) (16): 85-129.

Gligo, N. (1990): "Medio ambiente y recursos naturales en el desarrollo latinoamericano", en O. Sunkel (ed.), El desarrollo desde dentro: un enfoque neoestructuralista para América Latina, México, D.F., Fondo de Cultura Económica.

Guillen R. H., (2007). "De la orden CEPALina del desarrollo al neoestructuralismo en América Latina" Comercio Exterior, abril.

Hernández (2015) R. A., "Transformación del Estado y paradigmas de desarrollo en América Latina” en (Barcena, Prado, 2015).

Hodara, J., (1987), Prebisch y la CEPAL: Sustancia, Trayectoria y Contexto Institucional, El Colegio de México, México.

Kay, C., (1989), Latin American Theories of Development and Underdevelopment, Routledge, London, New York.

Kregel, Jan (2008): “The discrete charm of the Washington Consensus”, Working Papers, The Levy Economics Institute, No. 533.

Leiva, F., (2008), Latin American Neostructuralism. The Contradictions of Post-Neoliberal Development. 
Minneapolis: University of Minnesota Press.

Lustig, Nora (1988), "Del estructuralismo al neoestructuralismo: la búsqueda de un paradigma heterodoxo", Colección de Estudios CIEPLAN, No 23, Santiago de Chile.

Mateus, A., (1987), "Intervenciones" en el Coloquio de Madrid, "El Sistema Centro- Periferia en Transformación". Pensamiento Iberoamericano (Madrid) (11): 55-56. Enero-Junio.

Matos Mar, J., (1968), (comp.) La dominación de América Latina Amorrortu Editores. Argentina.

Mallorquin, Carlos, (2006), "Raúl Prebisch antes de la era de hielo”, Edgar J. Dosman (ed.), Raúl Prebisch - El poder, los principios y la ética del desarrollo. Banco Interamericano de Desarrollo. Interamericano de Desarrollo, BID, INTAL, Buenos Aires, Argentina,

-, (2013) Celso Furtado: un retrato intelectual, Universidad Autónoma de la Ciudad de México, México, 2013, Ciudad de México.

-, (2013a), "América Latina y su teoría", Estudios Críticos del Desarrollo, Universidad Autónoma de Zacatecas, vol. III, núm. 5, pp. 99-126.

-, (2013b), Relatos contados desde la periferia: el pensamiento económico latinoamericano, Plaza y Valdes, México.

-,(2014), "El laberinto del desarrollo sustentable", Estudios Críticos del Desarrollo, Universidad Autónoma de Zacatecas, vol. IV, núm. 6, 2014, pp. 59-93.

-, (2014a), "Las antinomias del desarrollo social sustentable en la periferia" en Margarita González Hernández (coord), Senderos de la insustentabilidad. degradacion humana y ambiental en el capitalismo neoliberal, Porrúa, Universidad Autónoma de Zacatecas.

-, (2015), “Lord Keynes después de su muerte, según Raúl Prebisch”, Estudios Críticos del Desarrollo, Universidad Autónoma de Zacatecas, vol. VI, núm. 9, 2015; pp. 173-228.

-,(2017), “'Quiero estudiar desarrollo económico. (O. Sunkel)', 'y eso qué es?'(L. Robbins)”; en Mallorquin (2017b, en prensa).

-, (2017a) "Discursos y saberes sustentables latinoamericanos", en Margarita González Hernández (coord), Privatización de los bienes comunes. discusiones en torno a la sustentabilidad, precarización y movimientos sociales, Porrúa, Universidad Autónoma de Zacatecas.

-, (2017b) América Latina y su teoría, Ariadna Ediciones, Santiago de Chile, Chile.

Meireles Monika (2016), Soberanía monetaria, desarrollo y pensamiento económico latinoamericano: enseñanzas de la dolarización ecuatoriana; Instituto de Investigaciones Económicas, UNAM, México.

Muñoz H., (ed), 1981, From Dependency to Development. Strategies to Overcome Underdevelopment and Inequality, Colorado, Westview.

Ocampo, J.A., C. Rada y L. Taylor (2009), Growth and Policy in Developing Countries: A Structuralist Approach, Oxford University Press.

Nadal, A. (2004) "Contradictions of the open economy model as applied in Mexico", in F. Ackerman; A. Nadal (eds), (2004) The Flawed Foundations of General...

Pérez Caldentey, E., (2105), "Una coyuntura propicia para reflexionar sobre los espacios para el debate y el diálogo entre el (neo)estructuralismo y las corrientes heterodoxas" en (Barcena, Prado, 2015).

Pinto A., (1983) "Centro-Periferia e industrialización. Vigencia y cambios en el pensamiento de la CEPAL, El Trimestre Económico, Vol. 50, No. 198(2), Número especial. 50 aniversario (Abril-Junio de 1983), pp. 1043-1076.

-, (1989), "Notas sobre la industrialización y progreso técnico en la perspectiva Prebisch- CEPAL", Pensamiento Iberoamericano (Madrid) (16):59-84. 
Prebisch, R. -, (1949a), Teoría dinámica de la economía (con especial aplicación a las economías latinoamericanas), documento mimeografiado. Biblioteca del Colegio de México. Puede verse en Raúl Prebisch. Obras 1919-1948, vol. IV.

- (1950), Crecimiento, desequilibrio y disparidades: interpretación en El Estudio Económico de América Latina 1949 Estudio Económico de América Latina 1949 (CEPAL), Santiago de Chile.

-, (1952), Problemas teóricos y prácticos del crecimiento económico, (CEPAL). Santiago de Chile.

-,(1970), Transformación y desarrollo. La gran tarea de la América Latina, México, D.F., Fondo de Cultura Económica.

-, (1971) "Tercera clase", el 13 de junio de 1971 en Santiago de Chile, Documentos, CEPAL, Biblioteca, Santiago de Chile.

-, (1981), Capitalismo periférico, crisis y transformación, México, D.F., Fondo de Cultura Económica.

-, (1983), "La teoría económica, el monetarismo y los países periféricos" (49), Los modelos de la crisis (comp.), Sohel Rifka, editorial El Conejo/ILDES, 1983, Quito, Ecuador.

-, (1993), Obras 1919-1949, vol. IV, Buenos Aires, Fundación Raúl Prebisch.

Ramos y O. Sunkel (1990): "Hacia una síntesis neoestructuralista", O. Sunkel (ed-), El desarrollo desde dentro: un enfoque neoestructuralista para América Latina. México, D.F., Fondo de Cultura Económica.

Rifka, S., (1983), Los modelos de la crisis, editorial El Conejo/ILDES, 1983, Quito, Ecuador.

Rosales, O., (1988a): “El neoestructuralismo en América Latina”, Pensamiento Iberoamencano”. Revista de Economía Política, no. 14, julio-diciembre.

-, (1988b), "Balance y Renovación en el Paradigma Estructuralista del Desarrollo Latinoamericano", en Revista de la CEPAL. No 34.

Sunkel O., (1968) "Política nacional de desarrollo y dependencia externa. En José Matos Mar, (1968), (comp.) La dominación de América Latina Amorrortu Editores. Argentina.

-,y Paz P., (1970), Subdesarrollo latinoamericano y la teoría del desarrollo, México, D.F., Siglo XXI Editores.

-,(1971) “Capitalismo transnacional y desintegración nacional en la América Latina. El Trimestre Económico vol.XXVIII, no. (38) 150; 525,585; también en Estudios Internacionales (Santiago de Chile) 4 (16): 3-61. Enero-Marzo de 1971.

-,(1977), "El desarrollo de la teoría del desarrollo". Estudios Internacionales (Santiago de Chile) 10 (40): 33-46. Octubre-Diciembre.

-,(1978), "La dependencia y la heterogeneidad estructural”. El Trimestre Económico (México)) 45 (177): 3-20. Enero-Marzo de 1978.

- Fuenzalida E. (1980), "La transnacionalización del capitalismo y el desarrollo nacional”, En Sunkel, Osvaldo, (1980) (et.,al); Transnacionalización y dependencia. Madrid, Ediciones Cultura Hispánica, Instituto de Cooperación Iberoamericana.

-Sunkel, (et.,al); (1980), Transnacionalización y dependencia. Madrid, Ediciones Cultura Hispánica, Instituto de Cooperación Iberoamericana.

-,Gligo N., (1980), Estilos de desarrollo y medio ambiente en la América Latina. México, Fondo de Cultura Económica, 1980. 2 vols. (El Trimestre Económico. Lecturas, N. 36).

-, (1981) "Development Styles and the Environment: An Interpretation of the Latin American Case" en Muñoz H., (ed), (1981), From Dependency to Development. Strategies to Overcome Underdevelopment and Inequality, Colorado, Westview.

-, (1984) "Pasado, presente y futuro de la crisis económica internacional", Revista de la CEPAL, no. 22. 
-, Griffith-Jones, S., (1986), Debt and Development Crises in Latin America, the End of an Illusion, (con Stephany Oxford University Press.

-, (1987), "Las relaciones Centro-Periferia y la transnacionalización”. Pensamiento Iberoamericano (Madrid) (11): 31-52. Enero- Junio.

-,(1987a), Intervenciones en el Coloquio de Madrid, "El Sistema Centro- Periferia en Transformación". Pensamiento Iberoamericano (Madrid) (11): 263-264; 296-297 y 350-351. Enero-Junio.

-, (1989) "Institucionalismo y estructuralismo". Revista de la CEPAL, no. 38, Santiago de Chile.

-,y G. Zuleta (1990), "Neoestructuralismo versus neoliberalismo en los años noventa", Revista de la CEPAL, No 42, Santiago de Chile.

-, (comp) (1991): El desarrollo desde dentro: un enfoque neoestructuralistapara América Latina, México, D.F., Fondo de Cultura Económica.

-,(1991a): "Del desarrollo hacia adentro al desarrollo desde dentro" en, El desarrollo desde dentro: un enfoque neoestructuralista para América Latina, México, D.F., Fondo de Cultura Económica.

-, (1991b) “Prólogo. En busca del desarrollo perdido”. “, en O. Sunkel ed. (1991).

-, (2005), "Conversación con Osvaldo Sunkel El desarrollo de América Latina ayer y hoy", Cuadernos del CENDES año $22 . \mathrm{n}^{\circ} 60$ tercera época septiembre-diciembre 2005.

-, (2006), "En busca del desarrollo perdido", Problemas del Desarrollo. Revista Latinoamericana de Economía, 2006 , 37 (147) UNAM, México.

Torres Olivos, M.., (2006) (comp), Fernando Fajnzylber Una visión renovadora del desarrollo de América Latina, Comisión Económica para América Latina y el Caribe (CEPAL), Santiago de Chile.

Ugarteche O., (2014), Historia crítica del Fondo Monetario Internacional, Instituto de Investigaciones Económicas-UNAM, México. 
Números anteriores:

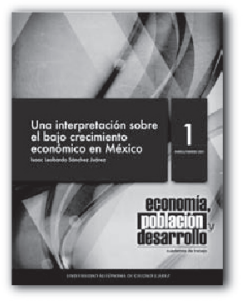

Economia, población y desartrollo. Cuadernos de trabajo
Enero-Febrero 2011

Una interpretación sobre el bajo Isaac Leobardo Sánchez Juárez
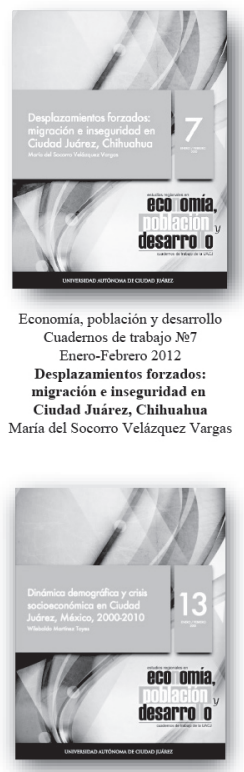

Economia, población y desarrollo Cuarednos de trabajo 013
Enero - Febrero 2013 Dinámica demográfica y crisis
socieconómica en Ciudad Juárez, México, 2000-2010

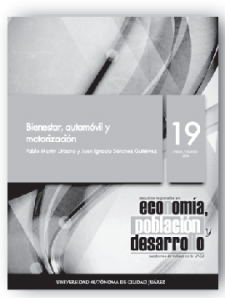

Economia, poblacín y desarrollo Enero - Febrero 2014 Bienestar, automóvil y motor Pablo Martin Urbano y
Juan Ignacio Sánchez Gutiérez
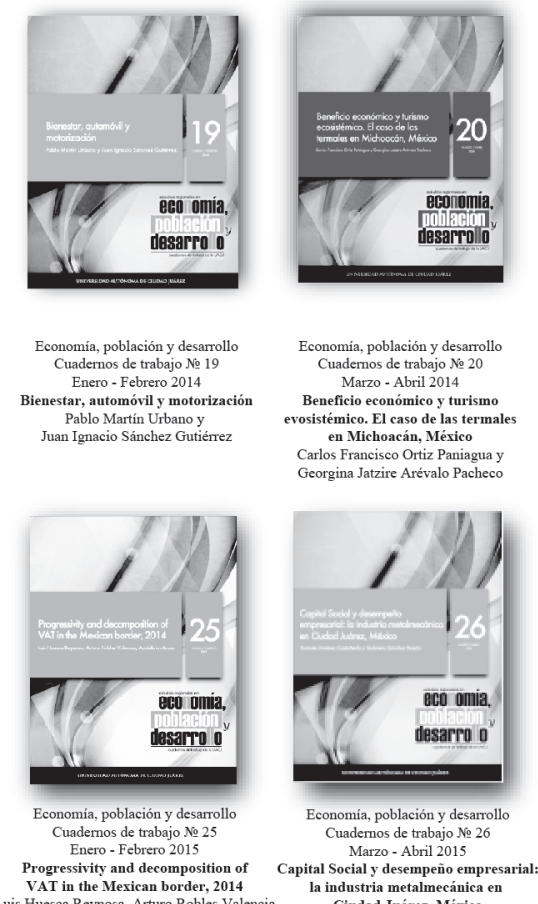

Economia, población y desarrollo Cuadernos de trabajo №
Marzo - Abril 2015 Capital Social y desempeño empresa la industria metalmecánica en
Cindad Juarez, México Ramsés Jiménez Castañeda
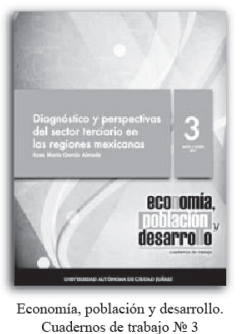

Mayo-Junio 2011

Diagnóstico y perspectivas

regiones mexicanas
rector terionarion en
Rosa Mária Gárcia Almad

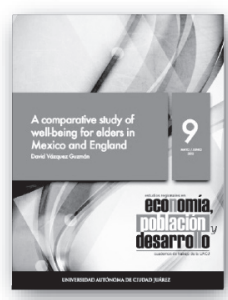

conomía, población y desarroll

Cuadernos de trabajo № 9
Mayo - Junio 2012

A comparative study of

Ueil-being for elders in

David Vízquez Guzón

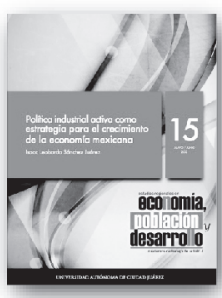

conomia, población y desarrollo

Mayo - Junio 2013

olítica industrial activa como

strategia para el creeimient
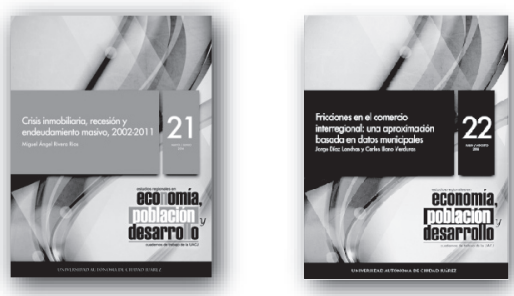

Economía, población y desarrollo

Crisis inmobiliaria, recesión y
endeudamiento masivo, $2002-2011$

Miguel Ángel Rivera Rios
Minol

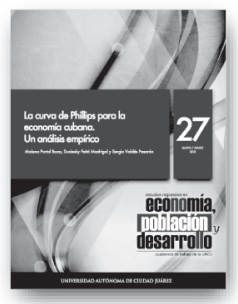

Economía, población y desarrollo

Cuademos de trabajo № 27 Mayo-Junio 2015
curva de Phillips pat

economia cubana.

Un análisis empírico Madrigal y Sergio Valdés Pasaró

Economía, población y desarrollo.

julio-Agosto 201

Los indices IDH y F FT en la

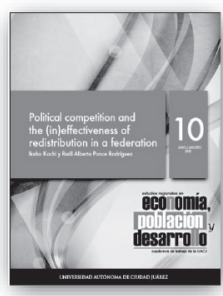

Cuadcrnos de trabajo №
Julio - Agosto 2012

Political competition and

edistribution in a federation

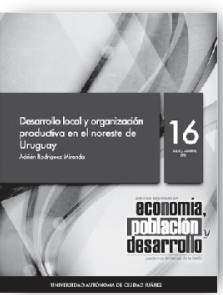

Economía, población y desarroll

Julio - Agosto 2014

Ficciones en el conercio basada en datos municipales
Joroc Diaz Lanchas $y$ Carlos .
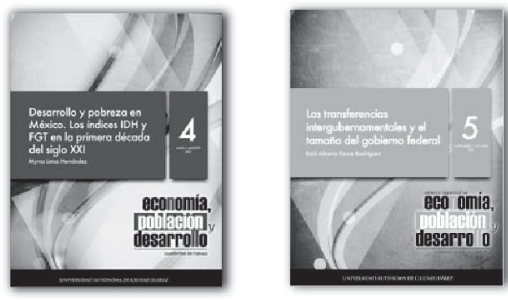

Economiá, población y desarroll

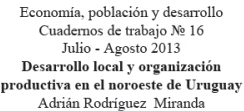

Cuadernos de trabajo № 17
Septiembre - Octubre 2013

ierabilidad social y vivie

en Sonora, Mexico
Jesús Enríquez Acosta

Sarah Bernal Salazar
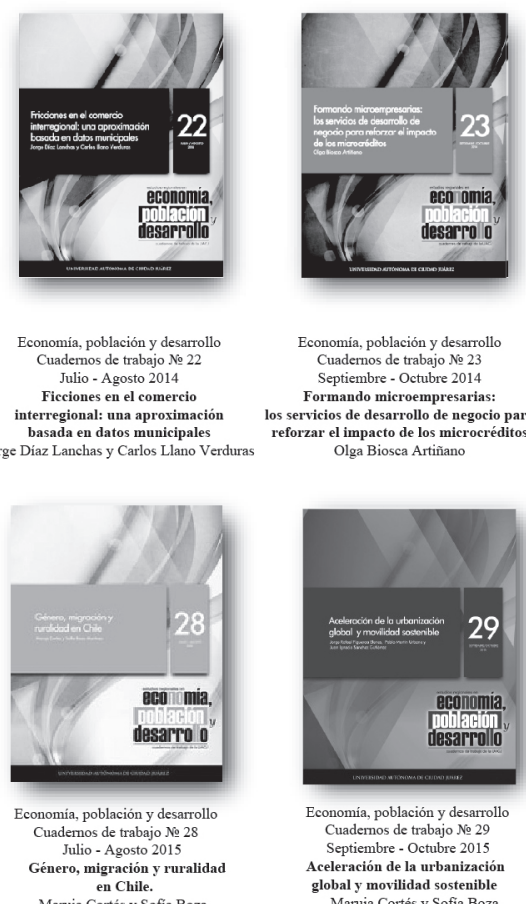

onomía, población y desarrollt

Septiembre - Octubre 201

Formando microempresarias:
servicios de desarrollo de negocio p forzar el impacto de los microcrédito

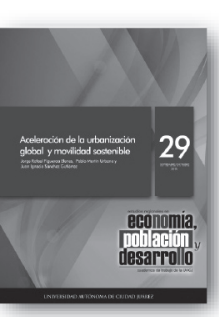

conomía, población y de Cuadernos de trabajo № 29
Septiembre - Octubre 2015 celeración de la urbanizacio global y movilidad sostenible

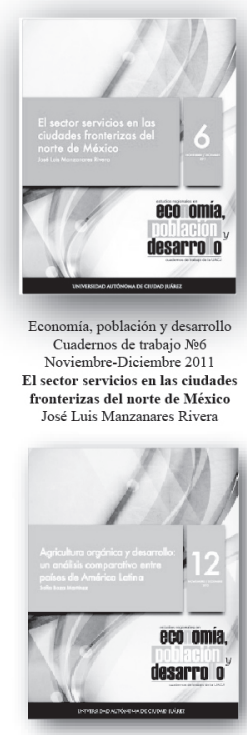

Economía, población y desarrollo Cuadcrnos de trabajo № 12 Noviembre - Diciembre 2012 $n$ análisis comparativo ent

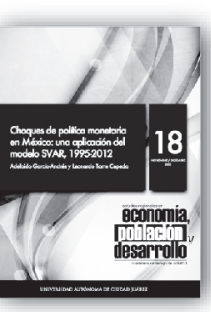

Economia, población y desarroll Cuadernos de trabajo № 18
Noviembre - Diciembre 2013 Choques de politica monetaria modelo SVAR, 1995-2012

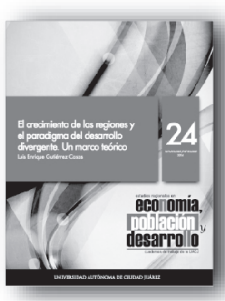

conomía, población y desarroll Cuadernos de trabajo № 24 El crecimiento de las regiones el paradigma del desarrollo divergente. Un marco teórico

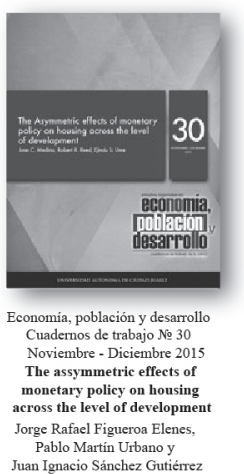


Números anteriores:

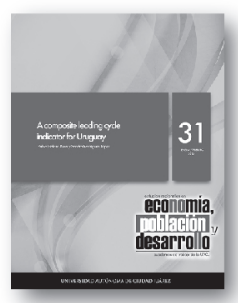

Economia, población y desarroll Cuadcrnos de trabajo № 31 A composite leading cycle indicator for Uruguay Pablo Galaso Reca y
Sandra Rodríguez López

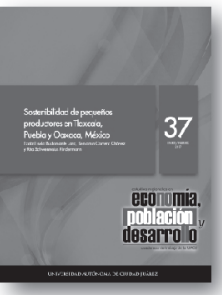
Cuadernos de trabajo № 37
Enero - Febrero 2017 Sostenibilidad de pequeño

productores en Taxcala,

Tratzil Iscla Bustamante Lara,

Benjamin Carrera Chávez y

Rita Schwentesius Rinderman

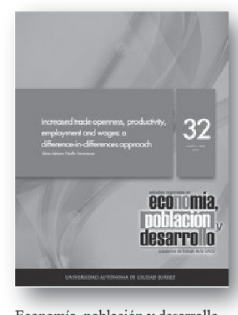

Economía, población y desarrollo Marzo - Abril 2016

Increased trade openness, productivity employment and wages: a difference -in-differences approac
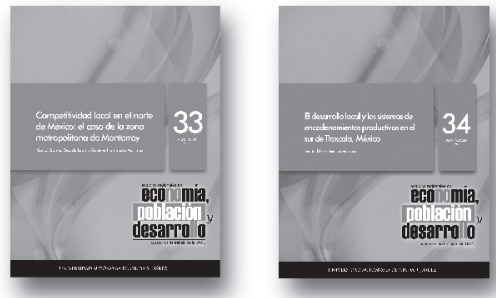

Economia, población y desarrollo Cuadcrnos de trabajo No
Mayo - Junio 2016

Competitividad local en el norte

de México: el caso de la zona

metropolitana de Monterrey

Gustavo Hernández Martíncz

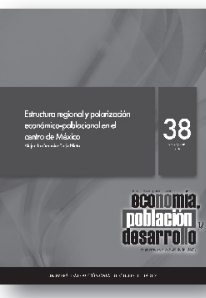

Economía, población y desarrolls Cuadernos de trabajo № 38
Marzo - Abril 2017 Estructura regional $y$

elarzación económico-poblacio Alcjandra Berenice Trejo Nieto

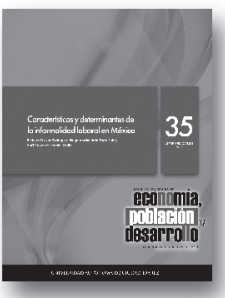

Economía, población y desarrollo Cuadernos de trabajo № 34 El desarrollo local y los sistemas de encadenamientos Tarela Mésico Maria del Pilar Jiméncz Márquezz

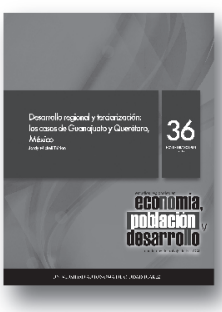

Economia, población y desarroll Septiembre - Oetubre 2016

Características y determinantes
de la informalidad laboral en Méxi

Enrique Cuevas Rodriguez, Hugo Antolin de la Torre Ruiz
Saúl Oswaldo Regla Dávila

conomía, población y desarrollo Noviembre - Diciembre 2016 Desarrollo regional y terciarización: los casos de Guanajuato y Querétaro, México
Jordy Micheli Thirión 


\section{$\rightarrow$ Normas Editoriales}

\section{Para el documento general:}

Tipo de letra: Times New Roman.

Tamaño: 11 puntos.

Interlineado: 1.5 espacios.

Títulos y subtítulos:

El texto principal en 11 puntos. Títulos 12 puntos (en resaltado). Subtítulos 11 puntos. Cada título y subtítulo deberá numerarse bajo el siguiente orden: $1,1.1,2,2.1,2.2 \ldots$

La extensión máxima de los cuadernos de trabajo será de 40 cuartillas.

La primera vez que se emplee una sigla en el texto se especificará primero su equivalencia completa y después la sigla.

\section{Hoja de presentación:}

Título:

14 puntos, centrado, resaltado.

Nombre de autor(es):

12 puntos

Resumen y abstract:

Debe incluir resumen en español y abstract (diez puntos), no mayor a 250 palabras

Palabras clave:

Incluir entre tres y cinco palabras clave, en español e inglés

Referencia del autor o autores:

Institución de adscripción, grado académico y líneas-grupos de investigación que desarrolla y a los que pertenece.

\section{Sistema de referencia de citas:}

Harvard-APA

Las citas bibliográficas en el texto deberán incluir entre paréntesis sólo el apellido del autor, la fecha de publicación y el número de página; por ejemplo: (Quilodrán, 2001: 33).

\section{Notación en sección de bibliografía y fuentes de información:}

Se deberá incluir al final del texto. Toda referencia deberá estar mencionada en el texto o notas de pie de página.

Cada referencia iniciará con el primer apellido o los apellidos, luego el nombre del autor, y después, entre paréntesis, el año de publicación seguido de un punto. Ejemplos:

Se deberá incluir al final del texto. Toda referencia deberá estar mencionada en el texto o notas de pie de página.

Cada referencia iniciará con el primer apellido o los apellidos, luego el nombre del autor, y después, entre paréntesis, el año de publicación seguido de un punto. Ejemplos:

Artículo:

Ros, Jaime (2008). "La desaceleración del crecimiento económico en México desde 1982”, en Trimestre Económico, vol. 75, núm. 299, pp. 537-560.

Libro:

Villarreal, René (2005). Industrialización, competitividad y desequilibrio externo en México. 
Un enfoque macroindustrial y financiero (1929-2010), México, Fondo de Cultura Económica. Capítulo de libro:

Castillo, Manuel Ángel (2003). "La política de inmigración en México: un breve recuento", en Manuel Ángel Castillo, Alfredo Lattes y Jorge Santibáñez (coords.), Migración y fronteras, Tijuana, El Colegio de la Frontera Norte / Asociación Latinoamericana de Sociología / El Colegio de México, pp. 425-451.

\section{Notas de pie de página:}

Se utilizarán para hacer indicaciones complementarias, aclaraciones o ampliación de una explicación. La notas de pie de página en Times New Roman, 10 puntos.

\section{Tipología de imágenes dentro del texto:}

Cuadro

Gráfica

Diagrama

Mapa

Figura

Todas las imágenes deben ser numeradas y mencionadas dentro del texto. A toda imagen debe incluirse la fuente.

Las indicaciones de la imagen: tipo y número de imagen, título de imagen y fuente se escriben en 10 puntos. En el texto poner como imagen los mapas, figuras, gráficas y diagramas -con el ánimo de no perder el formato realizado por el autor.

\section{Ecuaciones y fórmulas:}

Si se utilizan ecuaciones o fórmulas deberá utilizarse el editor de ecuaciones de Word y numerarse.

\section{Envío de trabajos}

Los trabajos deben ser enviados a la dirección de correo: lgtz@uacj.mx. Con el Dr. Luis Enrique Gutierrez Casas, editor de esta publicación.

La aceptación de cada colaboración dependerá de la evaluación de dos dictaminadores especialistas en la materia que se conservarán en el anonimato, al igual que el autor (autores) para efectos de la misma. 


\section{$\rightarrow$ Editorial Guidelines}

\section{For General Document:}

Font type: Times New Roman.

Size: font size 11 .

Paragraph: 1.5 line spacing.

Titles and subtitles: Main text font size 11. Titles font size 12 (Bold). Subtitles font size 11.

Each title and subtitle should be numbered in the following order: 1, 1.1, 2, 2.1, 2.2...

The maximum length of the workbooks will be 40 pages.

The first time an abbreviation is used in the text will be specified first complete equivalence and then stands.

\section{Front cover:}

Title:

Font size 14, centered, Bold.

Author name(s):

Font size 12.

Abstract:

It should include abstract in Spanish and abstract (font size 10), no more than 250 words.

Keywords:

Include three to five keywords, in Spanish and English.

Reference of author:

Institution of affiliation, academic degree and line-developed by research groups and belonging.

\section{Bibliographical appointment system:}

Harvard-APA

Citations in the text should include between parentheses only the author's name, publication date and page number, for example:

(Quilodrán, 2001: 33).

\section{Notation about Bibliography section and Information fonts:}

Should be included at the end of the text. All references must be mentioned in the text or footnotes page.

Each reference starts with the first name or last name, then the name of the author, and then, in parentheses, the year of publication followed by a period. Examples:

Article:

Ros, Jaime (2008). “La desaceleración del crecimiento económico en México desde 1982”, en Trimestre Económico, vol. 75, núm. 299, pp. 537-560.

Book:

Villarreal, René (2005). Industrialización, competitividad y desequilibrio externo en México. Un enfoque macroindustrial y financiero (1929-2010), México, Fondo de Cultura Económica.

Book chapter:

Castillo, Manuel Ángel (2003). "La política de inmigración en México: un breve recuento”, en Manuel Ángel Castillo, Alfredo Lattes y Jorge Santibáñez (coords.), Migración y fronteras, Tijuana, E1 Colegio de la Frontera Norte / Asociación Latinoamericana de Sociología / El Colegio de México, pp. 425-451. 


\section{Footnotes:}

Must be used to make additional indications, clarification or expansion of an explanation. The footnotes must be in Times New Roman, font size 10.

\section{Image typology inside text:}

Picture

Graph

Diagram

Map

Figure

All images must be numbered and mentioned in the text, should include the source image. The indications of the image: type and number of image, image title and source are written in 10 font size. In the text set as image maps, figures, graphs and charts-with the intention of not losing the formatting by the author.

\section{Equations and Formulae:}

When using equations or formulas should be used in Microsoft Word equation editor and numbered.

\section{Paper sending}

Entries must be sent to the email address: lgtz@uacj.mx. With Dr. Luis Enrique Gutiérrez Casas, editor of this publication.

Acceptance of each collaboration will depend on the evaluation of two examiners skilled in the art to be kept anonymous, like the author(s) for the same purposes. 


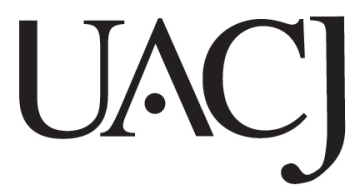

Esta obra se terminó de imprimir en abril de 2017

Cd. Juárez, Chihuahua, México.

Tiraje: 120 ejemplares 
Cuadernos de Trabajo de la Universidad Autónoma de Ciudad Juárez, número 39, mayo-junio de 2017

\section{Director y editor}

Dr. Luis Enrique Gutiérrez Casas

\section{Comité editorial}

Sección internacional

Dra. Sofía Boza Martínez (Universidad de Chile, Chile)

Dra. Olga Biosca Artiñano (Glasgow Caledonian University, Reino Unido)

Dra. Ángeles Sánchez Díez (Universidad Autónoma de Madrid, España)

Dr. Thomas Fullerton Mankin (University of Texas at El Paso, Estados Unidos)

Dr. Adrián Rodríguez Miranda (Universidad de la República, Uruguay)

\section{Sección local}

(Universidad Autónoma de Ciudad Juárez)

Dra. Myrna Limas Hernández

Dra. Ikuho Kochi

Dr. Raúl Alberto Ponce Rodríguez

Dr. Isaac Leobardo Sánchez Juárez

Dr. Héctor Alonso Barajas Bustillos

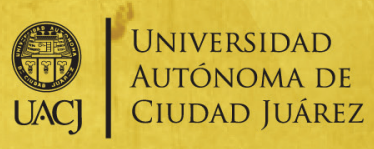

Universidad Autónoma de Ciudad Juárez Instituto de Ciencias Sociales y Administración

Cuadernos de Estudios Regionales en Economía, Población y Desarrollo ISSN 2007-3739

Cuerpo Académico de Estudios Regionales en Economía, Población y Desarrollo

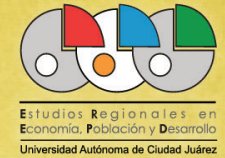

www.estudiosregionales.mx

\section{UAC CUERPOS ACADÉMICOS}

\section{Red}

Iberoamericana de Estudios del Desarrollo

Publicación afiliada a la Red Iberoamericana de Estudios del Desarrollo

(c) Universidad Autónoma de Ciudad Juárez Avenida Plutarco Elías Calles \#1210, Fovissste Chamizal Ciudad Juárez, Chih., México. www.uacj.mx 